\title{
Observing responses of chain-schedule stimuli and effects of $d-$ amphetamine and morphine
}

\author{
Jonathan M. Slezak \\ West Virginia University
}

Follow this and additional works at: https://researchrepository.wvu.edu/etd

\section{Recommended Citation}

Slezak, Jonathan M., "Observing responses of chain-schedule stimuli and effects of d-amphetamine and morphine" (2010). Graduate Theses, Dissertations, and Problem Reports. 3240.

https://researchrepository.wvu.edu/etd/3240

This Dissertation is protected by copyright and/or related rights. It has been brought to you by the The Research Repository @ WVU with permission from the rights-holder(s). You are free to use this Dissertation in any way that is permitted by the copyright and related rights legislation that applies to your use. For other uses you must obtain permission from the rights-holder(s) directly, unless additional rights are indicated by a Creative Commons license in the record and/ or on the work itself. This Dissertation has been accepted for inclusion in WVU Graduate Theses, Dissertations, and Problem Reports collection by an authorized administrator of The Research Repository @ WVU.

For more information, please contact researchrepository@mail.wvu.edu. 
Observing Responses of Chain-Schedule Stimuli and Effects of $d$-Amphetamine and Morphine

Jonathan M. Slezak

\author{
Dissertation submitted to the \\ Eberly College of Arts and Sciences \\ At West Virginia University \\ in partial fulfillment of the requirements \\ for the degree of \\ Doctor of Philosophy \\ in \\ Psychology
}

Karen G. Anderson, Ph.D., Chair

Kennon A. Lattal, Ph.D.

Michael Perone, Ph.D.

Constance Toffle, Ph.D.

Oliver Wirth, Ph.D.

Department of Psychology

Morgantown, West Virginia

2010

Keywords: observing, chain schedules, delay-reduction hypothesis, bipolar model, $d$ amphetamine, morphine, pigeon 


\begin{abstract}
Observing Responses of Chain-Schedule Stimuli and Effects of $d$-Amphetamine and Morphine

Jonathan M. Slezak

There is an inherent confound when utilizing response-dependent chain schedules to examine conditioned reinforcement effects because the same response is required for the production of both conditioned and primary reinforcers. The present study utilized an observing response to examine the conditioned-reinforcing value of stimuli in a three-link chain variable-time schedule, which allows for the removal of the response-reinforcer contingency of typical chain schedules. In Experiment 1, observing was maintained by the production of stimuli correlated with links of a chain VT schedule, indicating conditioned reinforcing properties of all or some of the chain stimuli. To test if performance under chain schedules is maintained via backward transmission of reinforcer value (i.e., a classical-conditioning interpretation of chain performance), extinction and prefeeding conditions were implemented. No evidence of a backward transmission of reinforcer value was found when examining either the entire chain or just the first two links; however, results were generally consistent with predictions based on the delay-reduction hypothesis. In Experiment 2, effects of $d$-amphetamine and morphine were tested to determine if the conditioned reinforcer efficacy of chain stimuli would be enhanced selectively by administration of a stimulant drug. Results did not support prior literature suggesting that only stimulant drugs enhance the efficacy of conditioned reinforcers, but were supportive of a ratedependency interpretation. Overall, effects across drug and nondrug disruptors were consistent and suggest disruption of a common behavioral mechanism that may fit within the framework of a bipolar model of behavior within clocked interfood intervals.
\end{abstract}




\section{Acknowledgments}

I would like to thank the members of my dissertation committee, Karen Anderson, Mike Perone, Andy Lattal, Oliver Wirth, and Constance Toffle for their thoughtful comments and discussion regarding this research. I am indebted to Dr. Anderson for her outstanding mentorship. Karen has been extremely supportive in my development as a behavioral researcher. I am deeply thankful to my lab mates Natalie Bruner, James Diller, Christopher Krebs and Sally Huskinson for the strong camaraderie in the Anderson Lab. I thank Roger Escober for the many fruitful discussions on observing. I also am very appreciative of Dr. Sherry Serdikoff for getting me involved in the science of behavior. Finally, I thank my family because none of this would have been possible without them. I especially thank Natalie Bruner for her continuous encouragement and support throughout our graduate careers. 
Table of Contents

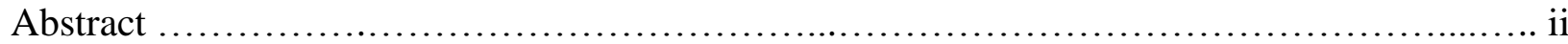

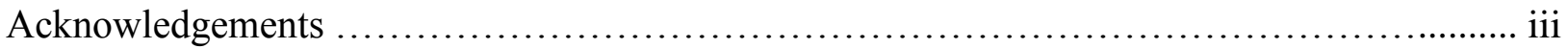

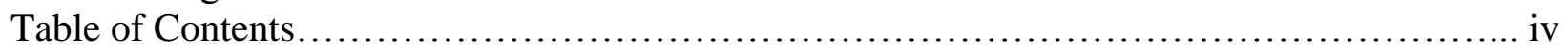

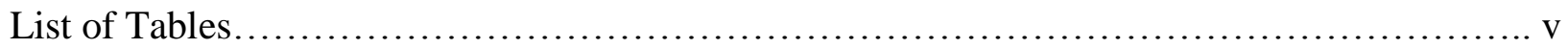

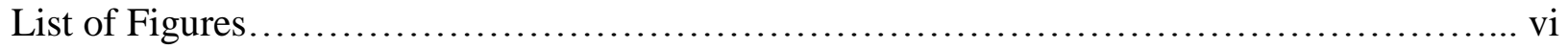

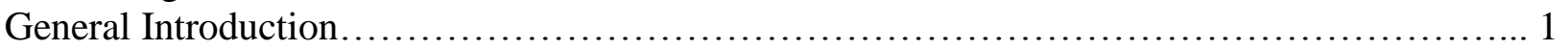

Chain Schedules......................................................... 1

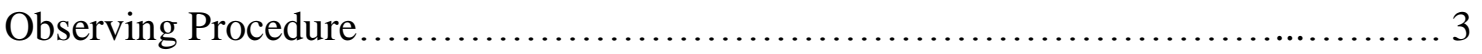

Observing and Chain Schedules ..............................................4

Classical-Conditioning View of Chain Performance............................... 7

Stimulant Drugs and Conditioned Reinforcement.................................9

Statement of the Problem.......................................................... 11

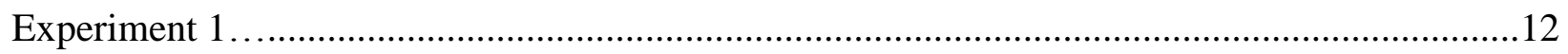

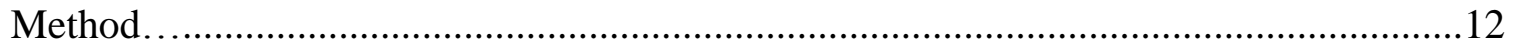

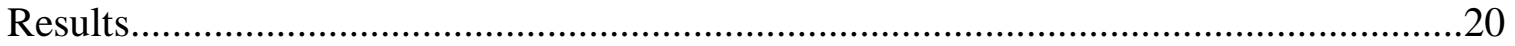

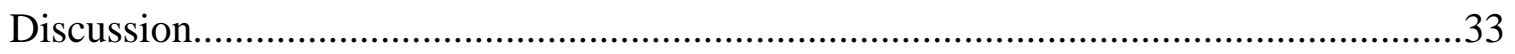

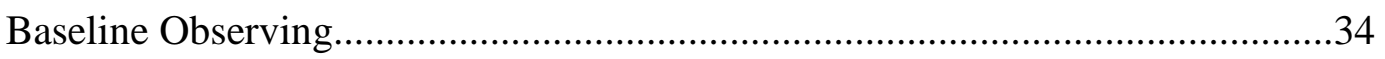

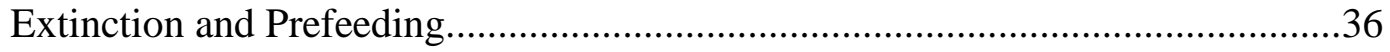

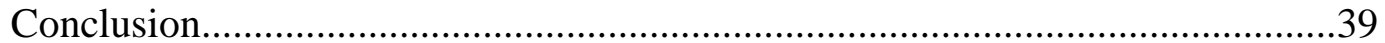

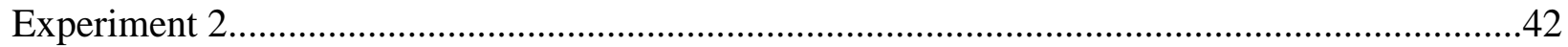

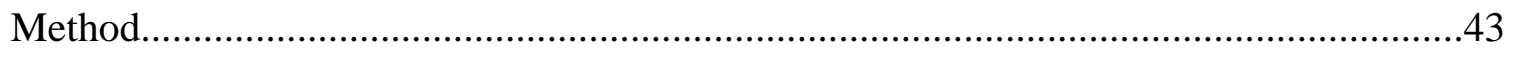

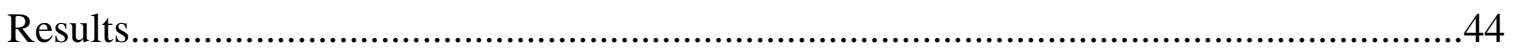

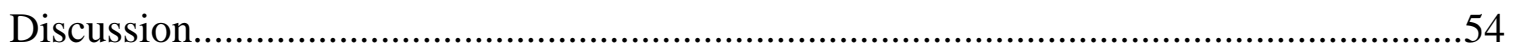

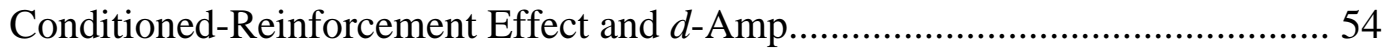

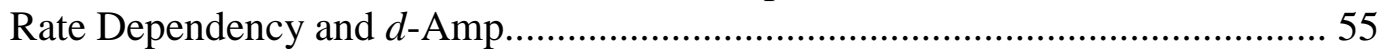

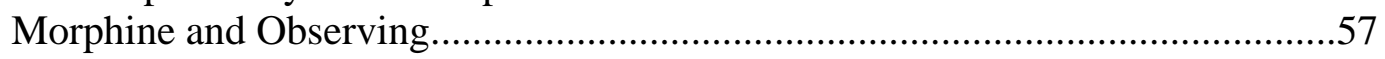

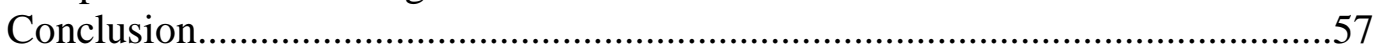

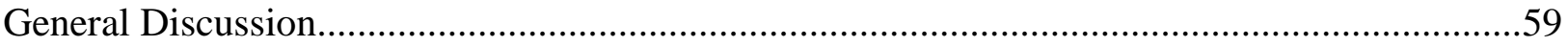

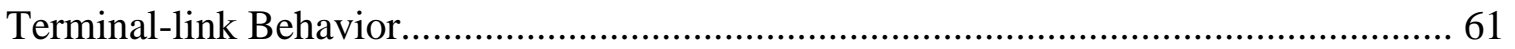

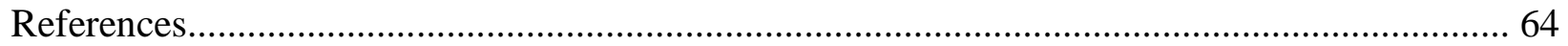




\section{List of Tables}

Table 1: A list of experimental parameters in Experiments 1 and 2..........................

Table 2: Statistics from linear regression analyses in Experiment $1 \ldots \ldots \ldots \ldots \ldots \ldots \ldots \ldots \ldots \ldots . . . \ldots 29$ 


\section{List of Figures}

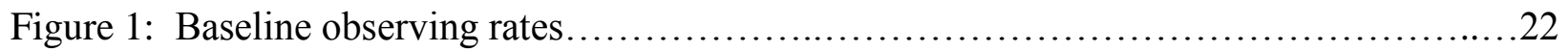

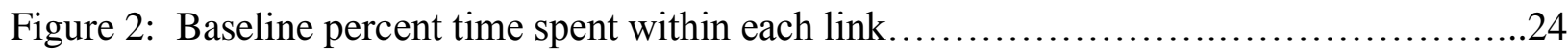

Figure 3: Absolute observing rate during extinction sessions .............................27

Figure 4: Observing rate during extinction sessions as a proportion of baseline...............28

Figure 5: Absolute observing rate during prefeeding sessions........................... 31

Figure 6: Observing rate during prefeeding sessions as a proportion of baseline................32

Figure 7: Average absolute observing rate after administration of $d$-amp $\ldots \ldots \ldots \ldots \ldots \ldots \ldots . \ldots 46$

Figure 8: Average observing rate after administration of $d$-amp as a proportion of saline........47

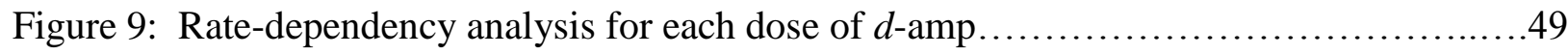

Figure 10: Average absolute observing rate (resp/min) after administration of morphine.......51

Figure 11: Average observing rate after administration of morphine as a proportion of saline..52

Figure 12: Rate-dependency analysis for each dose of morphine $\ldots \ldots \ldots \ldots \ldots \ldots \ldots \ldots \ldots \ldots . .53$ 


\section{General Introduction}

Human behavior is often maintained by stimuli that do not have direct biological necessity. That is, much of human behavior is maintained by stimuli that become reinforcers only through experience (i.e., conditioned reinforcers). People will work for money because of its relation with primary reinforcement and not because money has some intrinsic value. Williams (1994, p. 261) describes that an "initially neutral event acquires value because of its relation to primary reinforcement, and subsequently can serve as an effective reinforcer in its own right." The relevance of conditioned reinforcement in understanding basic behavioral processes is evident by the rich history of theorizing and experimentation concerning this topic (e.g., Kelleher \& Gollub, 1962; Fantino, 1977; Dinsmoor, 1983; Williams, 1994).

There are a number of preparations utilized to assess conditioned reinforcement such as extinction procedures, second-order schedules, chain schedules, and observing procedures. Each method has entailed considerable debate in terms of its efficacy in examining and assessing conditioned reinforcement effects (see Williams, 1994 for a concise review). An overall objective of the present experiment was to investigate the conditioned-reinforcing value of the schedule-correlated stimuli of a chain schedule.

\section{Chain Schedules}

A chain schedule consists of two or more links, which are each signaled by a distinct stimulus. The consecutive completion of each link in a chain results in primary-reinforcer delivery after the terminal link. Responding in early links of a chain may be maintained by the conditioned-reinforcing value of stimulus onset accompanied by subsequent links (Kelleher \& Gollub, 1962). As an example, take the behavioral chain of preparing spaghetti and meatballs. The links could consist of buying the groceries, boiling the pasta, draining the pasta, making the 
meatballs, frying the meatballs, mixing the meatballs, pasta and sauce, and finally enjoying the well-cooked dinner. Each link in the chain could serve as a conditioned reinforcer for responding in the previous link until the meal is eventually consumed (i.e., primary reinforcement).

Support for the conditioned reinforcement view of chain-schedule performance comes from an unpublished dissertation by Gollub (as cited in Kelleher \& Gollub, 1962), in which a tandem fixed-interval (FI) 1-min FI 1-min schedule was first established with pigeons as subjects. The only difference between a tandem and chain schedule is that a tandem schedule has the same stimulus context throughout all links until primary-reinforcer delivery. After maintaining key pecking under the tandem schedule, the schedule was switched to a chain FI 1min FI 1-min schedule, so there were distinct stimuli correlated with each link. This manipulation resulted in increases in responding during the initial chain FI link relative to the initial tandem FI link, which supports a conditioned reinforcement interpretation of chainschedule performance. However, Kelleher and Fry (1962) established a three-link schedule by maintaining key pecking under a tandem FI 1-min FI 1-min FI 1-min schedule that was subsequently switched to a chain FI 1-min FI 1-min FI 1-min schedule. They found that initial link responding was greater during the tandem relative to the chain schedule. If it was the conditioned-reinforcing value of stimulus onset that maintained responding in early links, then response rates should have been elevated in the chain relative to the tandem schedule (cf. Royalty, Williams, \& Fantino, 1987).

An opposing interpretation of chain-schedule performance is that responding within each link of a chain is controlled exclusively by the discriminative value of the link stimuli signaling the delay to primary reinforcement, and not the conditioned-reinforcing value of the link stimuli 
(e.g., Staddon \& Cerutti, 2003). There is an inherent confound when utilizing chain procedures such that the same response is required for the production of both conditioned and primary reinforcers. It is difficult to determine the underlying process when the conditioned-reinforcing value of a stimulus is determined by the same response that produces primary reinforcement. Despite this confound, there has been additional evidence supporting a conditioned reinforcement view of chain-schedule performance.

Royalty, Williams, and Fantino (1987) established a baseline chain variable-interval (VI) 33-s VI 33-s VI 33-s schedule. After stability was met on the baseline schedule, they systematically imposed an unsignaled 3-s delay between one of the link transitions, and modified the chain schedule to a chain VI 30-s VI 30-s VI 30-s schedule to account for changes in reinforcement rate. Overall, the unsignaled delay decreased response rates in the link with a delay, but not the other links. This effect is consistent with a conditioned reinforcement account of chain-schedule performance, and similar to effects of delay to primary reinforcement (e.g., Sizemore \& Lattal, 1978). Comparable results of delayed conditioned reinforcement have also been obtained with an observing procedure (e.g., Lieving, Reilly, \& Lattal, 2006), which is considered the optimal test of conditioned reinforcement (Dinsmoor, 1983; Williams, 1994). There is reasonable evidence that chain-schedule stimuli may function as conditioned reinforcers and their function could be investigated further by use of an observing procedure.

\section{Observing Procedure}

Wyckoff (1952) first developed the observing procedure in which food delivery maintained key pecking and the production of schedule-correlated stimuli maintained treadle pressing. The baseline schedule of reinforcement was an FI schedule that alternated with extinction in a mixed schedule format (i.e., the food key remained white when the FI schedule or 
extinction was in effect). When the treadle was pressed, schedule-correlated stimuli were produced (i.e., the mixed schedule was converted into a multiple schedule), but the treadle press did not alter the rate of food delivery. It was found that a high rate of observing (i.e., treadle pressing) occurred, but it was unclear if observing responses were maintained only by the conditioned reinforcing effect of S+ presentations (i.e., the stimulus correlated with food). Numerous studies since the seminal Wyckoff experiment have examined whether it was the production of S+, the production of S- (extinction-correlated stimulus), or both, that were maintaining the observing response (see Fantino, 1977; Dinsmoor, 1983). The majority of experimental results with nonhuman subjects indicate that presentation of S- alone does not maintain observing responses, and that observing is consistent with effects of conditioned reinforcement (i.e., a neutral stimulus acquiring reinforcer value because of the relation between the neutral stimulus and primary reinforcement).

As demonstrated in Wyckoff's (1952) study, "the observing response has no appreciable effect on the schedule on which primary reinforcement is delivered, it can also be used as a behavioral sensor or transducer" (Dinsmoor, 1983, p. 696). An important advantage to examining conditioned reinforcement with an observing procedure is that the critical response is maintained by stimulus production alone (e.g., S+) and does not directly influence the rate of food delivery. Thus, as a behavioral sensor, the observing response could be used as a measure of the conditioned-reinforcing value of stimuli within different arrangements of reinforcement schedules such as chain schedules.

\section{Observing and Chain Schedules}

As there is evidence to suggest that chain stimuli may have conditioned-reinforcing value, a next step would be to examine if chain stimuli maintain an observing response. Hendry 
and Dillow (1966) were able to maintain observing for stimuli associated with links of a chain FI 1-min FI 1-min FI 1-min schedule. In Experiment 1, two different schedules of observing were examined: a VI 3-min observing schedule that resulted in $15 \mathrm{~s}$ of schedule-correlated stimuli or an fixed-ratio (FR) 1 that resulted in $0.1 \mathrm{~s}$ production of chain stimuli. The responses per minute on the observing key across the three FI links in each condition were 6.4, 12.3, 7.5 and 6.9, 19.5, 9.6, respectively. Thus, in both observing conditions they found that observing increased as the chain progressed until the last link, where there was a slight decrease likely due to increased pecking on the food key. Response competition during an observing procedure with responsedependent schedules has been previously suggested (e.g., Kendall, 1965; Hendry \& Dillow, 1966; Kendall, 1972; Case and Fantino, 1981; Shahan, 2002).

Hendry and Dillow (1966) interpreted their results as the chain stimuli having conditioned-reinforcing value. The value was differentiated across the three links of the FI schedule, with the potential of earlier link stimuli functioning as S- (see Kendall, 1972 for a discussion). Although it has been debated (e.g., Royalty, Williams, \& Fantino, 1987) that early link stimuli in chain schedules may have an S- function, it seems that the underlying process of observing in chain schedules may be best described in terms of the delay-reduction hypothesis of conditioned reinforcement (Fantino, 1977). The basic assumption of this hypothesis is that the conditioned-reinforcing value of a stimulus depends on the overall reduction in the delay to primary reinforcement that a stimulus signals relative to the previous stimulus context. For example, in the Hendry and Dillow study, the stimulus associated with the terminal FI should have maintained the most observing and relatively less observing within the middle and initial links. This pattern of observing would be due to the fact that the average time to food signaled by the initial-link stimulus was $3 \mathrm{~min}, 2 \mathrm{~min}$ by the middle-link stimulus, $1 \mathrm{~min}$ by the terminal- 
link stimulus, and 2 min by the tandem stimulus. This pattern of behavior was not observed, likely due to response competition between the food and observing key within the terminal link. Overall, the delay-reduction hypothesis of conditioned reinforcement has been deemed adequate to account for maintenance of observing, and is suggested to be in agreement with the classicalconditioning view of conditioned reinforcement (e.g., Dinsmoor, 1983; Williams, 1994).

Royalty, Williams, and Fantino (1987) suggested that one technique to investigate conditioned reinforcement in chain schedules may be to examine response-independent stimulus change (i.e., converting a chain FI 30-s FI 30-s FI 30-s schedule into a multiple extinction (EXT) 30-s EXT 30-s FI 30-s schedule, see Catania, Yohalem, \& Silverman, 1980). This method is still confounded because the same response that is utilized as a measure of conditioned-reinforcing value is the same response that produces primary reinforcement. However, when utilizing a three-link chain fixed-time (FT) or variable-time (VT) schedule, and an observing response as the measure of conditioned reinforcement, the response-reinforcer confound in typical chain schedules would be absent. That is, conditioned-reinforcing value of chain stimuli would not be measured by response rates in each link, but instead by an observing response that does not appreciably alter the rate of food delivery. In addition, there have been a number of studies demonstrating the maintenance of observing responses with response-independent schedules alternating with extinction (e.g., Fantino \& Case, 1983; Dinsmoor, Bowe, Green, \& Hanson, 1988; Tomanari, Machado, \& Dube, 1998). In order to investigate further the conditionedreinforcing value of chain stimuli, a chain VT schedule with an observing contingency was established in the present set of experiments. This arrangement has the benefit of eliminating the response-reinforcer relation of typical chain schedules, and also potentially decreasing effects of response competition that may be found in observing procedures with response-dependent food 
schedules (e.g., Kendall, 1965; Hendry \& Dillow, 1966; Kendall, 1972; Shahan, 2002). The stimuli of chain schedules have been demonstrated to maintain observing responses (e.g., Hendry \& Dillow, 1966), and a chain VT schedule may isolate the stimulus-stimulus relation and provide an adequate measure of conditioned reinforcer value.

\section{Classical-Conditioning View of Chain Performance}

The classical-conditioning view of conditioned reinforcement and chain-schedule performance (see Kelleher \& Gollub, 1962; Williams, 1994) suggests that a neutral stimulus gains conditioned-reinforcing value by being paired with a primary reinforcer via first-order conditioning. Thus, for stimuli in chain schedules, there is higher-order conditioning that results in backward transfer of reinforcer value from the primary reinforcer to the stimuli in the previous links (e.g., S3 $\leftarrow \mathrm{S} 2 \leftarrow \mathrm{S} 1 \leftarrow \mathrm{SR}$, with S3 as the initial-link stimulus, S2 as the middle-link stimulus, and $\mathrm{S} 1$ as the terminal-link stimulus resulting in primary reinforcement, denoted by SR, after completion). If this process holds, then effects of extinction should also occur in a backward manner to remain consistent with a classical-conditioning interpretation of chainschedule performance. That is, responses during S3 are maintained by S2 presentation, responses during S2 are maintained by S1 presentation, and responses during S1 are maintained by primary reinforcement (Bell, Goldenberg, \& McDevitt, 2007). Removal of the primary reinforcer should decrease S1 responding first, then S2, and then S3.

A number of recent experiments have addressed the classical-conditioning interpretation of chain-schedule performance (Williams, Ploog, \& Bell, 1995; Williams, 1997; 1999; Bell, Goldenberg, \& McDevitt, 2007), with the latter experiment most relevant to the present studies. Bell, Goldenberg, and McDevitt exposed pigeons to two alternating chain VI VI VI schedules, with an intertrial interval (ITI) bisected by 3-s access to grain. After stable responding was 
observed under both chain schedules, one of the terminal link stimuli was devalued in an attempt to increase the rate of response reduction in a subsequent extinction condition. The devaluation sessions consisted of alternations of both terminal-link stimuli with one of the terminal links followed by no food (i.e., extinction). The chains were then reinstated, and extinction was in effect for both chain schedules. The results of their study were inconsistent with a classicalconditioning interpretation of conditioned reinforcement. During two conditions, extinction affected initial and middle links equally, and in a third condition, the results were more consistent with a forward pattern of extinction (i.e., greater response rate reduction in the initial link). The authors suggested that the presence of the ITI food, which was included to keep the overall stimulus context consistent during extinction, might have affected the extinction results. Another analysis of resistance-to-change (i.e., disruptive procedures, such as extinction, used to change the ongoing rate of behavior) in chain schedules was conducted by Nevin, Mandell, and Yarensky (1981). The baseline schedule consisted of 2 two-link random-interval (RI) chain schedules that alternated irregularly on different keys. Across experimental conditions, either reinforcer duration or reinforcer duration and rate were manipulated. In each condition, key pecking under the alternating chain schedules was disrupted by either signaled concurrent reinforcement on a third key or prefeeding subjects one hour prior to the start of experimental sessions. The consistent result across conditions was that key pecking was more resistant to change in the terminal link relative to the initial link (i.e., key pecking decreased at a greater rate during the initial link). These findings are contrary to predictions based on a classical-conditioning interpretation of chain performance. As tests of resistance-to-change may be a critical manipulation in examining the classical-conditioning view of chain-schedule 
performance, Experiment 1 of the present set of studies contained extinction and prefeeding conditions.

\section{Stimulant Drugs and Conditioned Reinforcement}

Another environmental variable that may affect observing is administration of stimulant drugs (e.g., methylphenidate, $d$-amphetamine), which are commonly prescribed for children with behavioral disorders (e.g., Northup, Fusilier, Swanson, Roane, \& Borrero, 1997). This drug class has been associated with enhancing effects of a conditioned reinforcer (e.g., Robbins, Watson, Gaskin, \& Ennis, 1983; Mazurski \& Beninger, 1986; Files, Branch, \& Clody, 1989; Ranaldi \& Beninger, 1993). For example, Cohen and Branch (1991) established a baseline rate of responding in pigeons under a second-order schedule, with completion of a VI resulting in either food or a brief food-paired stimulus, or a brief non-paired stimulus. After $d$-amphetamine $(d$ amp) administration, greater increases in response rates relative to baseline rates were found during a signaled extinction component with a stimulus previously paired with food, than in a signaled extinction component with a stimulus not previously paired with food. Thus, a conditioned reinforcer (i.e., a stimulus paired with food) and not stimulus change alone (i.e., a stimulus not paired with food) resulted in increased response rates after $d$-amp administration.

The experimental preparations used to examine the relation between stimulant drugs and conditioned reinforcement have mainly consisted of variations of extinction or second-order schedules (e.g., Robbins, Watson, Gaskin, \& Ennis, 1983; Mazurski \& Beninger, 1986; Cohen \& Branch, 1991; Ranaldi \& Beninger, 1993). Fewer studies (e.g., Clark, 1969; Raiff \& Dallery, 2006) have examined drug effects ( $d$-amp and nicotine, respectively) and conditioned reinforcement within an observing procedure. In a study most similar to the present experiments, Branch (1975) established observing (1.5-s stimulus duration) under a simple FI 120-s food 
schedule with pigeons as subjects. A single observing response (FR 1) resulted in the production of stimuli correlated with thirds of the FI (i.e., a stimulus correlated for every $40 \mathrm{~s}$ of the FI). Baseline observing was similar to the results found by Hendry and Dillow (1966) in that observing rates increased from the initial third to the second third of the interval, and then decreased during the interval closest to food delivery. Separate administration of $d$-amp and chlorpromazine both resulted in proportional increases in the first third of the FI, decreases in the second third and no change or a decrease in the interval closest to food. Thus, the behavior of the two pigeons analyzed in this study did not clearly demonstrate a conditioned reinforcement enhancing effect due to stimulant drug administration (see also Clark, 1969). The most consistent demonstration of a stimulant enhancing conditioned-reinforcer efficacy in an observing procedure comes from Raiff and Dallery (2006; 2008). Using a procedure similar to Wyckoff's (1952) preparation, they found that acute administration of the stimulant drug nicotine resulted in increases in observing rates of rats relative to observing rates after saline administration.

Included in the present set of experiments (Experiment 2) was an attempt to replicate previous findings (e.g., Robbins, Watson, Gaskin, \& Ennis, 1983; Mazurski \& Beninger, 1986) that stimulant drugs may enhance responding maintained by a conditioned reinforcer (i.e., increase rates of observing) relative to saline in the proposed variation of the observing procedure developed by Wyckoff (1952). More specifically, a range of doses $(0.3-3.0 \mathrm{mg} / \mathrm{kg})$ of $d$-amp were administered after establishing stable observing rates. After a range of dose effects were obtained, effects of a drug outside the stimulant pharmacological class (morphine, $1.0-5.6 \mathrm{mg} / \mathrm{kg}$ ) were tested. This was conducted to determine if only the stimulant drug class would result in increases in observing rates (cf., Branch, 1975). 


\section{Statement of the Problem}

The overarching objectives of the present set of experiments were to examine the conditioned-reinforcing value of stimuli associated with links of a chain schedule (as measured by observing) and assess certain predictions for the maintenance of behavior under chain schedules of reinforcement. The typical measure of the conditioned-reinforcing value of chain stimuli associated with response-dependent schedules (i.e., response rates in each link) is confounded because the same response also results in primary reinforcement. The present experiments were conducted in order to isolate the conditioned-reinforcing value of chain stimuli by removing the response reinforcer contingency, which has led to different interpretations of behavior maintained under chain schedules of reinforcement. For example, the discriminative value of the link stimuli signaling the delay to primary reinforcement may be maintaining behavior under chain schedules, and not the conditioned-reinforcing value of the link stimuli.

To examine conditioned reinforcement in chain schedules, an observing response was used as the measure of conditioned reinforcement value of stimuli in a three-link chain VT schedule. Based upon predictions derived from the delay-reduction hypothesis of conditioned reinforcement, observing under a three-link VT chain schedule (with links of equal duration) should be highest in the terminal link because it is the only stimulus that signals a reduction in delay relative to tandem conditions. To examine the classical-conditioning interpretation of chain-schedule performance, certain disruptors (i.e., extinction and prefeeding) were implemented in Experiment 1 to assess how observing changes across each link as a function of changes to the primary reinforcer. In Experiment 2 , the previous finding that stimulant drugs enhance the efficacy of conditioned reinforcers was examined by administering $d$-amp followed by morphine as a potential negative control. The stimulant-enhancing effect of conditioned reinforcement was investigated because no study using an observing procedure and $d$-amp has resulted in a robust replication of findings from research 
that comprise of alternative assessments of conditioned reinforcement (e.g., extinction or secondorder schedules).

\section{Experiment 1}

Subjects

\section{Method}

Four experimentally naive male Carneau pigeons served as subjects. They were maintained at $80 \%(+/-15 \mathrm{~g})$ of their free-feeding body weight and fed accordingly, 30 minutes after each session. Each subject had free access to water and health grit in the homecages.

\section{Apparatus}

Four operant-conditioning chambers located in sound-attenuating enclosures were used in this experiment. Each chamber measured $305 \mathrm{~mm}$ wide by $335 \mathrm{~mm}$ deep and $375 \mathrm{~mm}$ tall. An aluminum panel comprised the front wall of the chambers. Three translucent plastic keys, 25 $\mathrm{mm}$ in diameter, were located on the aluminum panel, $265 \mathrm{~mm}$ from the chamber floor. The centers of the keys were $90 \mathrm{~mm}$ apart, and the leftmost key was $70 \mathrm{~mm}$ from the left edge of the chamber. Each key could be transilluminated by four or five $28-\mathrm{V}$ miniature lamps that were covered by colored lens caps or a colored film. Mixed grain was delivered via a food hopper that could be raised into a 65 - by $55-\mathrm{mm}$ opening in the front panel of the chamber. The bottom edge of the opening was located $180 \mathrm{~mm}$ below the center of the center key. A white lamp above the food hopper was illuminated when grain was presented. A ventilation fan circulated air and masked extraneous noise throughout the experimental session. All experimental events were controlled by a computer running MedAssociates® software, and programs were written by the author using MedState ${ }^{\circ}$ notation.

\section{Key Peck Training}


All sessions took place at approximately the same time each day, seven days per week. After magazine training, key pecking was established by reinforcing successive approximations of the target response (i.e., pecking the center key that was transilluminated white) with 4-s access to mixed grain. A white center key later served as the observing key. After key pecking was established, a continuous-reinforcement procedure (i.e., grain presentation for each peck on the center key) was implemented for approximately five sessions (30 grain presentations per session).

\section{Chaining Procedure}

A prior goal of this experiment was to examine effects of forward vs. backward chaining of the link stimuli; however, following exposure to the chaining procedure, observing was not maintained. Therefore, different procedures were used to establish observing and thus, the examination of different pairing techniques was no longer relevant to the present experiment. Following the initial failure to maintain observing, a number of manipulations (see below) were conducted to establish observing.

Two pigeons (C1 and D1) had backward chaining and two pigeons (C4 and D4) had forward chaining of the link stimuli. Description of the color and location of the link stimuli can be found in Table 1. Each stimulus-pairing condition lasted for four sessions, which resulted in 160 food-stimulus pairings within each condition. The selection of the number of pairings was based on Mazurski and Beninger (1986) and Ranaldi and Beninger (1992), which utilized 160 food-stimulus pairings within a partial-pairing procedure across four sessions. Only the backward chaining procedure is described in detail. The forward chaining procedure was identical to backward chaining except the initial stimulus paired with food was S3, then S3 and $\mathrm{S} 2$, and then $\mathrm{S} 3, \mathrm{~S} 2$, and $\mathrm{S} 1$. 
Table 1

A list of experimental parameters for individual subjects during Experiments 1 and 2 and the color and location of chain stimuli.

\begin{tabular}{|c|c|c|c|c|}
\hline Subject: & C1 & C4 & D1 & D4 \\
\hline Side-key location & Left & Right & Left & Right \\
\hline S3 color & Purple & Red & Purple & Red \\
\hline S2 color & Green & Yellow & Green & Yellow \\
\hline S1 color & Amber & Blue & Amber & Blue \\
\hline Baseline schedule & VT 55 VT 55 VT 55s & VT $32.5 \mathrm{VT} 32.5 \mathrm{VT} 32.5 \mathrm{~s}$ & VT 55 VT 55 VT 55 s & $\begin{array}{l}\text { VT } 32.5 \text { VT } 32.5 \text { VT } 32.5 \mathrm{~s} \\
\text { *VT } 42.5 \text { VT } 42.5 \text { VT } 42.5 \mathrm{~s}\end{array}$ \\
\hline Schedule progression & n $10-100$ s by 10 & $10-55$ s by 5 & $10-100$ s by 10 & $\begin{array}{l}10-55 \text { s by } 5 \\
* 10-75 \text { s by } 5\end{array}$ \\
\hline Number of trials & 30 & 40 & 30 & $\begin{array}{r}40 \\
* 28\end{array}$ \\
\hline
\end{tabular}
$*$ The numbers denoted by the asterisk indicate that D4 was switched to a different terminal baseline schedule due to difficulties
reestablishing baseline performance after the extinction condition. 
S1 pairing condition. At the start of the first pairing session, a side key (see Table 1) was transilluminated amber or blue (see S1 in Table 1) and all other keys were dark. Food was delivered on a VT 32.5-s schedule (arithmetic progression found in Table 1). Food presentation consisted of darkening the side key, turning on the hopper light and presenting grain for $4 \mathrm{~s}$. After each food presentation, an intertrial interval (ITI) of $30 \mathrm{~s}$ was implemented in which the entire chamber was dark. This condition lasted four sessions (40 food presentations per session).

S2-S1 pairing condition. At the start of the fifth pairing session, a chain VT 32.5-s VT 32.5-s schedule was implemented. On the side key there was a green or yellow initial-link stimulus (see S2 in Table 1), and an amber or blue stimulus (S1) in the terminal link. All other keys remained dark. Food presentations and ITI length were the same as the previous condition and lasted four sessions (40 food presentations per session).

S3-S2-S1 pairing condition. At the start of the ninth pairing session, a chain VT 32.5-s VT 32.5-s VT 32.5-s schedule was implemented. On the side key, there was a purple or red initial-link stimulus (see S3 in Table 1), green or yellow middle-link stimulus (S2), and an amber or blue stimulus (S1) in the terminal link. All other keys remained dark. Food presentations and ITI length were the same as previous conditions and lasted four sessions (40 food presentations per session).

Observing Procedure

At the start of each observing session, the chain VT 32.5-s VT 32.5-s VT 32.5-s schedule (same as in the S3-S2-S1 pairing condition) was implemented for 10 consecutive presentations. After the 10 chain stimuli presentations, a tandem VT 32.5-s VT 32.5-s VT 32.5-s schedule was implemented on the side key for 30 consecutive presentations, with both the side and center key transilluminated white. A single response on the center key resulted in darkening of that key for 
$3 \mathrm{~s}$ and the transillumination of the side key with the appropriate schedule-correlated stimulus for $3 \mathrm{~s}$. That is, an FR 1 schedule was implemented on the center key, which served as the observing key. Observing responses resulted in the stimulus (white) correlated with the tandem schedule changing to the appropriate chain-correlated stimulus on the side key. The initial-link stimulus (S3) was purple or red, the middle-link stimulus (S2) was green or yellow, and the terminal-link stimulus (S1) was amber or blue.

Similar to Lieving, Reilly, and Lattal (2006), the chain stimulus could be terminated prior to $3 \mathrm{~s}$ if the initial link transitioned to the middle link, if the middle link transitioned to the terminal link, or if food was delivered. Food presentations and ITI length were the same as previous conditions for both the 10 chain presentations and the tandem-schedule presentations. To minimize adventitious reinforcement of key pecking prior to food delivery, food was not presented within $2 \mathrm{~s}$ of a peck on the observing key or a peck on the side key if transilluminated white (both of these events rarely occurred during baseline conditions). Key pecking could occur immediately prior to food delivery if a side key was illuminated with a schedule-correlated stimulus to avoid the development of negative auto-maintenance (Williams \& Williams, 1969).

\section{Additional Manipulations}

Observing was not established with exposure to the Observing Procedure. The first manipulations successful in establishing observing in one subject $(\mathrm{C} 4)$ was to double the ITI to $60 \mathrm{~s}$ and increase the observing duration to full-link observing (i.e., one response on the observing key produced the appropriate schedule-correlated stimulus for the remainder of that particular VT value). After establishing observing, the observing duration was gradually faded down to $5 \mathrm{~s}$ across sessions. For the other subjects, these manipulations did not aid in 
establishing observing and the schedule was changed back to the chain VT 32.5-s VT 32.5-s VT 32.5-s schedule (see S3-S2-S1 pairing condition) for approximately five sessions.

In accordance with the delay-reduction hypothesis, as a means to increase the conditioned-reinforcing value of the chain stimuli, the chain VT 32.5-s VT 32.5-s VT 32.5-s schedule was switched to a chain VT 55-s VT 55-s VT 55-s schedule for C1, C4, and D4 for approximately five sessions. The observing contingency was then reinstated as described in the Observing Procedure, but this was not sufficient to establish observing. The next manipulation was to provide exposure to the chain and tandem schedules without the observing contingency. This is similar but not identical to training found in other studies on observing (e.g., Defulio \& Hackenberg, 2008). These schedule changes occurred across sessions for D1 in which four sessions consisted of the presentation of the chain stimuli on the side key (i.e., S3-S2-S1 pairing condition) and then four sessions with just the tandem stimulus (white) on the side key. For subjects C1 and D4 this was accomplished within session. For four sessions, the tandem stimulus and chain stimuli alternated on the side key every three trials for subjects C1 and D4. The observing contingency was then reinstated (after eight sessions for D1 and four sessions for $\mathrm{C} 1$ and D4) and the observing duration was full-link observing (i.e., one response on the observing key produced the appropriate schedule-correlated stimulus for the remainder of that VT value). Observing was maintained for D1 and C1, but not D4. The observing duration was then gradually faded down for D1 and C1 to $5 \mathrm{~s}$ in duration.

Subject D4 returned to chain and tandem schedule within-session exposures for six sessions. Based upon results with subjects not used in the present experiment, a fading procedure was utilized with D4 to establish observing. Similar to the Observing Procedure used for all subjects, the first 10 trials consisted of chain schedule presentations only. On the $11^{\text {th }}$ 
trial, the side key was transilluminated white during the S3 and then S2 link, but the observing key remained dark. When transitioning to the S1 link the observing key was transilluminated white and one response would produce the schedule-correlated stimulus until food delivery (i.e., full-link observing). On the $21^{\text {st }}$ trial, the observing key was transilluminated white during both S2 and S1 links for the remaining trials (30 total trials) and observing had the same consequence. After two sessions of the fading procedure, the duration of the S3 link was manipulated based on previous observation that S3 may have aversive properties. For example, with subjects not used in the present experiment, there was difficulty maintaining observing when S3 was introduced during the fading procedure. In addition the production of S3 resulted in subjects turning away from the key and flapping their wings (see Dinsmoor, Lee, \& Brown, 1986, for a discussion of similar effects). The VT duration during S3 was initially $5 \mathrm{~s}$, while the VT duration was still 55 $\mathrm{s}$ for the other two links. The VT values were then titrated across sessions to a point where observing was maintained within each link (a terminal value of VT $32.5 \mathrm{~s}$ in each link). In addition, the observing duration was concurrently faded down to $5 \mathrm{~s}$ in duration.

\section{Baseline Observing}

The terminal observing duration ( $5 \mathrm{~s}$ for each subject) was in effect for a minimum of 15 sessions. Before assessing stability and implementing the extinction condition, the 10 chain presentations at the start of each session were removed in order to eliminate a potential confound in later data interpretation. The 10 chain presentations were left out of the remaining experimental conditions and did not systematically alter the ongoing rate of observing across subjects. The terminal baseline conditions (i.e., no chain presentations and 5-s observing duration) were in effect for a minimum of six sessions and continued until stability was met. Stability during baseline observing conditions was determined via examination of observing 
rates in each link across the last six sessions. Stability was met if no increasing or decreasing trends in observing rates were found within each link across the last six sessions. The terminal schedule values and number of trials within a session for each subject can be found in Table 1 .

\section{Extinction}

This condition was identical to baseline observing except grain was not delivered after completion of the chain. At the end of the terminal link (S1), the key lights and house light were extinguished, the hopper light was turned on, and an empty hopper was raised for $4 \mathrm{~s}$ followed by the 60 -s ITI. Observing had the same consequence as the previous condition. The extinction condition terminated following 10 sessions (e.g., Bell \& Gomez, 2008) or until a session consisted of 5 min without an observing response (not including the ITI). Due to experimenter error for subject D4, the extinction condition ended at the end of 5 min without an observing response and not at the end of the complete session that consisted of 5 min without an observing response. After the extinction condition, the baseline observing condition was reinstated for a minimum of 10 sessions.

Prefeeding

This condition was identical to baseline observing except subjects were fed $30 \mathrm{~g}$ of grain one hour prior to each session (e.g., Shahan \& Podlesnik, 2008). The prefeeding condition terminated following 10 sessions or until a session consisted of 5 min without an observing response (not including the ITI). After the prefeeding condition, the baseline observing condition was reinstated.

\section{Data Analysis}

Individual subject data are presented within each figure and table. The average observing rate producing each schedule-correlated stimulus during the last six stable sessions was 
compared across subjects. Observing rates were calculated by taking the total number of responses during the tandem stimulus and dividing by the time spent in the presence of the tandem stimulus (e.g., DeFulio \& Hackenberg, 2008). The percentage of the session spent in the presence of each schedule-correlated stimulus (e.g., Shahan, 2002) during the last six stable sessions was compared across subjects. The proportion of observing rates during extinction sessions relative to the average observing rate from the last six baseline sessions was calculated. This proportion (extinction observing/average baseline observing) was then plotted on a logarithmic scale which is common in resistance-to-change studies (e.g., Nevin, Mandell, \& Yarensky, 1981) and standardization of the y-axis allows for a direct comparison across subjects. In addition, slopes of the extinction functions from the plots were obtained via linear regression (e.g., Nevin, 1992). The same analyses and plots for the extinction condition were also performed for the prefeeding condition.

\section{Results}

\section{Baseline}

Figure 1 shows the baseline observing rate across each link for each subject during the last six sessions prior to extinction (first panel) and prefeeding (second panel) conditions. The same overall pattern of observing across each link was observed for each subject in the first baseline condition although there was some variability in absolute rate. The terminal-link stimulus (S1) maintained the lowest rate of observing. Relative to S1, higher rates of observing were maintained by the intial-link stimulus (S3). Production of the middle-link stimulus (S2) maintained the highest observing rate. This overall pattern of observing was reliable during both baseline conditions; however there was a baseline shift for subject $\mathrm{C} 4$ for the production of the middle-link stimulus following extinction (i.e., an increase in observing of S2). It should also be noted that for subject D4, the baseline food delivery schedule changed after extinction (see Table 
1) due to difficulties maintaining stable observing rates. Despite the change in the rate of food delivery, the same pattern of observing was maintained for subject D4. 


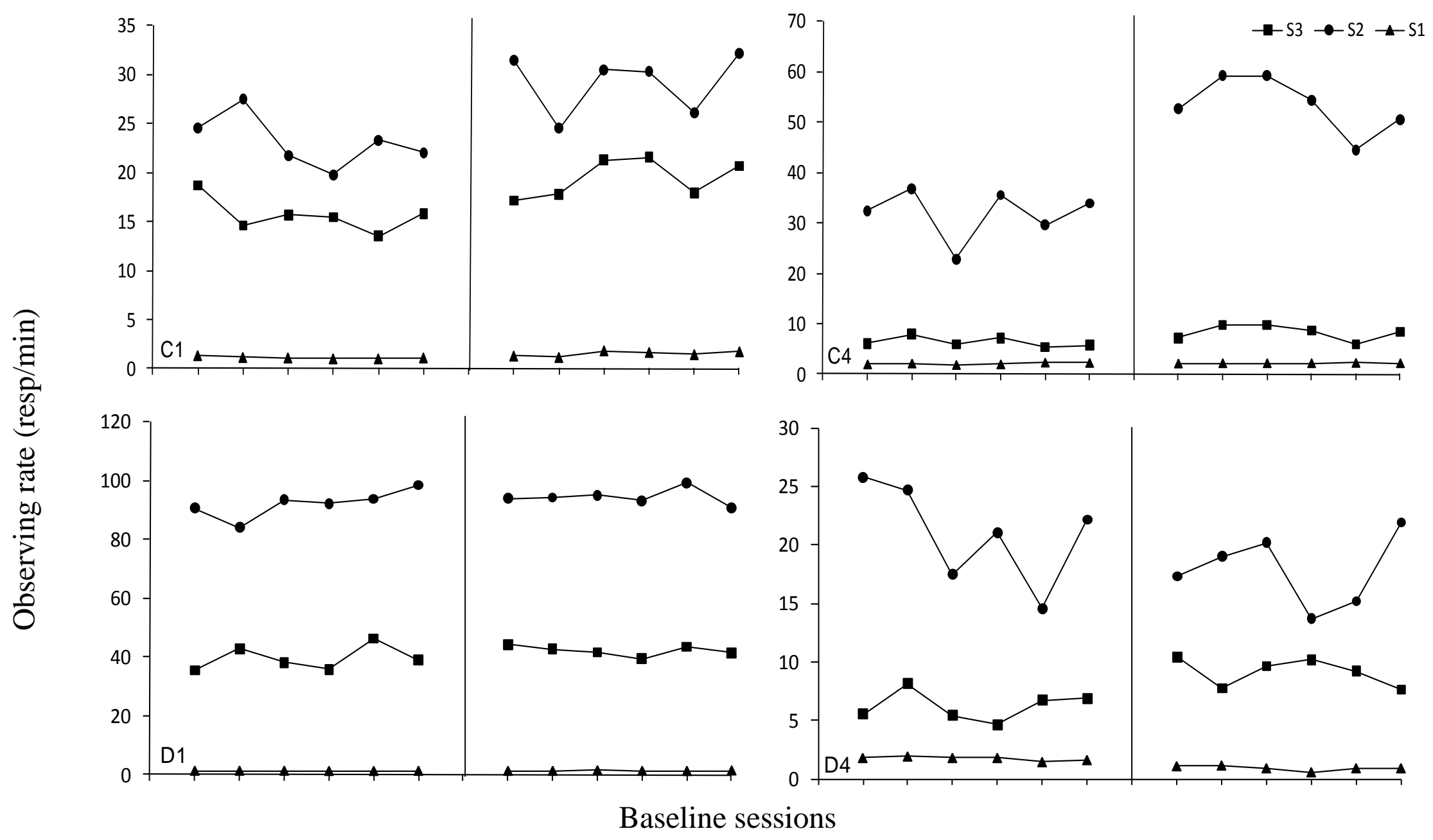

Figure 1. Observing rate (resp/min) during the last six baseline sessions across the S3 link (filled squares), S2 link (filled circles) and S1 link (filled triangles) prior to extinction (left panel) and prior to prefeeding (right panel) for each subject. The subject number is located in the lower left corner of each set of graphs. Notice scaling differences on the y-axis. 
The time spent in the presence of each schedule-correlated stimulus during baseline sessions (see Figure 2) parallel the results found with the absolute rate of observing. The percent of time spent in the presence of the middle-link stimulus (S2) was the highest, followed by the initial-link stimulus (S3), and then the terminal-link stimulus (S1). Similar to the rate of observing, there was variation across subjects in the degree of time spent in the presence of each stimulus. The overall pattern of time spent in the presence of each schedule-correlated stimulus, however, remained the same across subjects in both baseline conditions. 

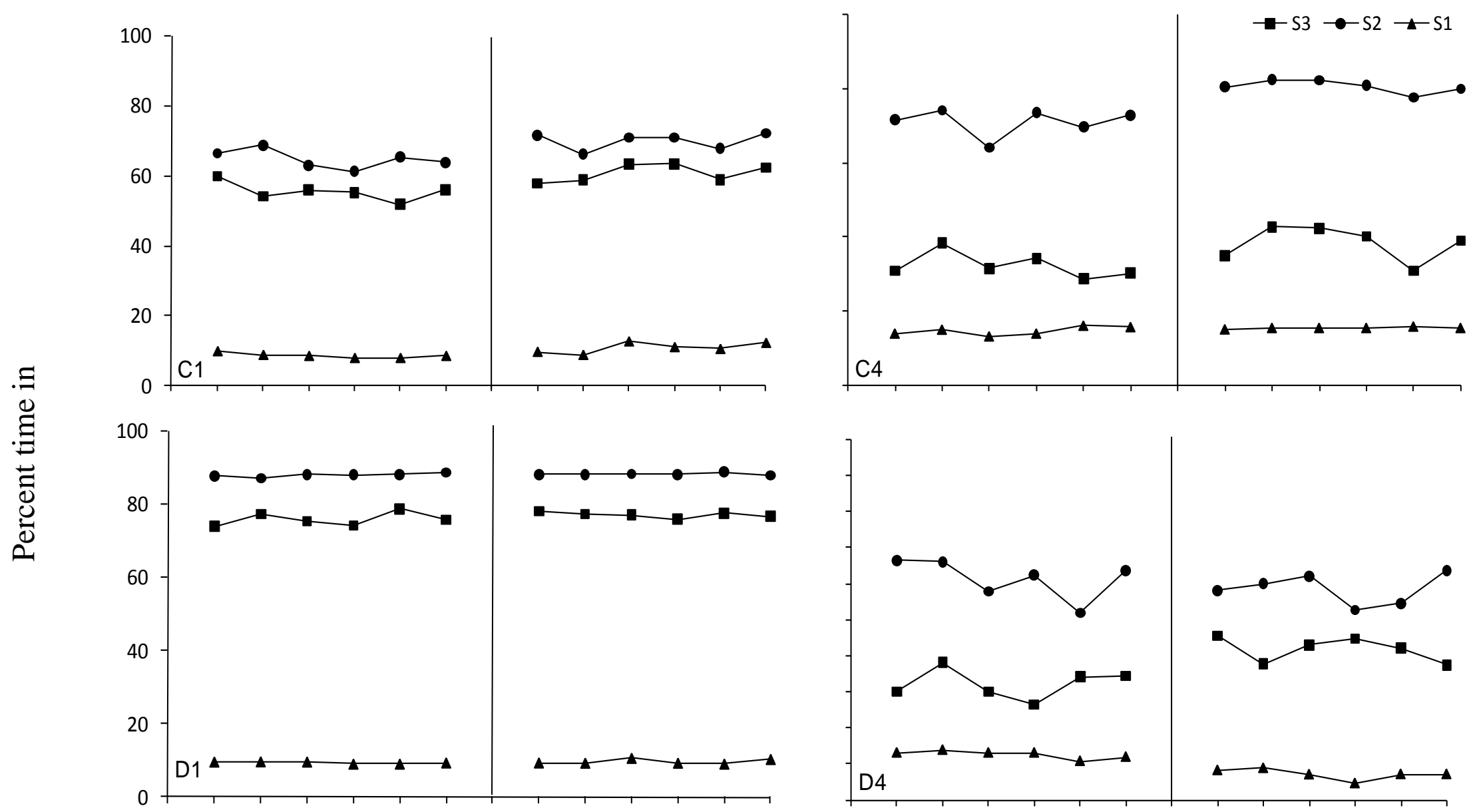

Baseline sessions

Figure 2. The percent time spent within each link during the last six baseline sessions across the S3 link (filled squares), S2 link (filled circles) and S1 link (filled triangles) prior to extinction (left panel) and prior to prefeeding (right panel) for each subject. The subject number is located in the lower left corner of each set of graphs. 
Anecdotal evidence obtained via video-monitoring equipment suggests that after producing the terminal-link stimulus from zero to two times (approximately 0 - $10 \mathrm{~s}$ of terminallink stimulus presentation), a specific pattern of behavior was exhibited by each subject that may have been adventitiously reinforced via response-independent food deliveries. This was most evident for subject D4. For example, if facing the key panel, this subject (D4) would typically begin to peck the right corner of the operant-conditioning chamber after production of the terminal-link stimulus. The most common pattern of behavior observed with the other three subjects was pacing in front of the key panel or corner of the key panel. This superstitious behavior may have competed with observing of the terminal-link stimulus and thus resulted in observing rates lower than initial- and middle-link rates.

To quantify when observing responses occurred within the terminal link (S1 link averaged $55 \mathrm{~s}$ for subjects $\mathrm{C} 1$ and D1, $32.5 \mathrm{~s}$ for subjects C4 and D4), the time from terminal link onset relative to each observing response within the terminal link was calculated for the last three baseline sessions prior to extinction. The median and range for the time between terminal link onset and each observing response within the terminal link for subjects C1, C4, D1, and D4 were $M d n=1.18 \mathrm{~s}(0.21-7.53 \mathrm{~s}), M d n=0.81 \mathrm{~s}(0.03-31.21 \mathrm{~s}), M d n=0.54 \mathrm{~s}(0.10-2.88 \mathrm{~s}), M d n=0.79$ s (0.10-18.74 s), respectively. The absolute number of observing responses within the terminal link ranged from zero to two responses across subjects. These results indicate that the majority of observing responses within the terminal link occurred immediately after the onset of the terminal link and provides support that behavior other than observing occurred prior to food delivery.

Extinction 
Figure 3 shows effects of extinction on absolute observing rates relative to the average performance across the last six baseline sessions and Figure 4 shows effects of extinction across each extinction session as a proportion of baseline performance. Any points above the dotted line in Figure 4 indicate that observing rates increased relative to baseline performance and points below the dotted line indicate that observing rates decreased relative to baseline performance. Across extinction sessions for each subject there was an increase in production of the terminal-link stimulus (S1) that either sustained (subjects C1 and D1) or eventually decreased below baseline levels (subjects C4 and D4) by the final extinction session. The proportional decrease in observing of the terminal-link stimulus across all extinction sessions for each subject was always less than that found with observing of the middle- or initial-link stimulus. The pattern of decline in the observing rate between middle- (S2) and initial-link (S3) stimuli across extinction sessions for each subject appeared to be quite similar. The functions for subjects $\mathrm{C} 1$ and D4 in Figure 4, however, indicate that observing first decreased below baseline levels in the initial link relative to the middle link 

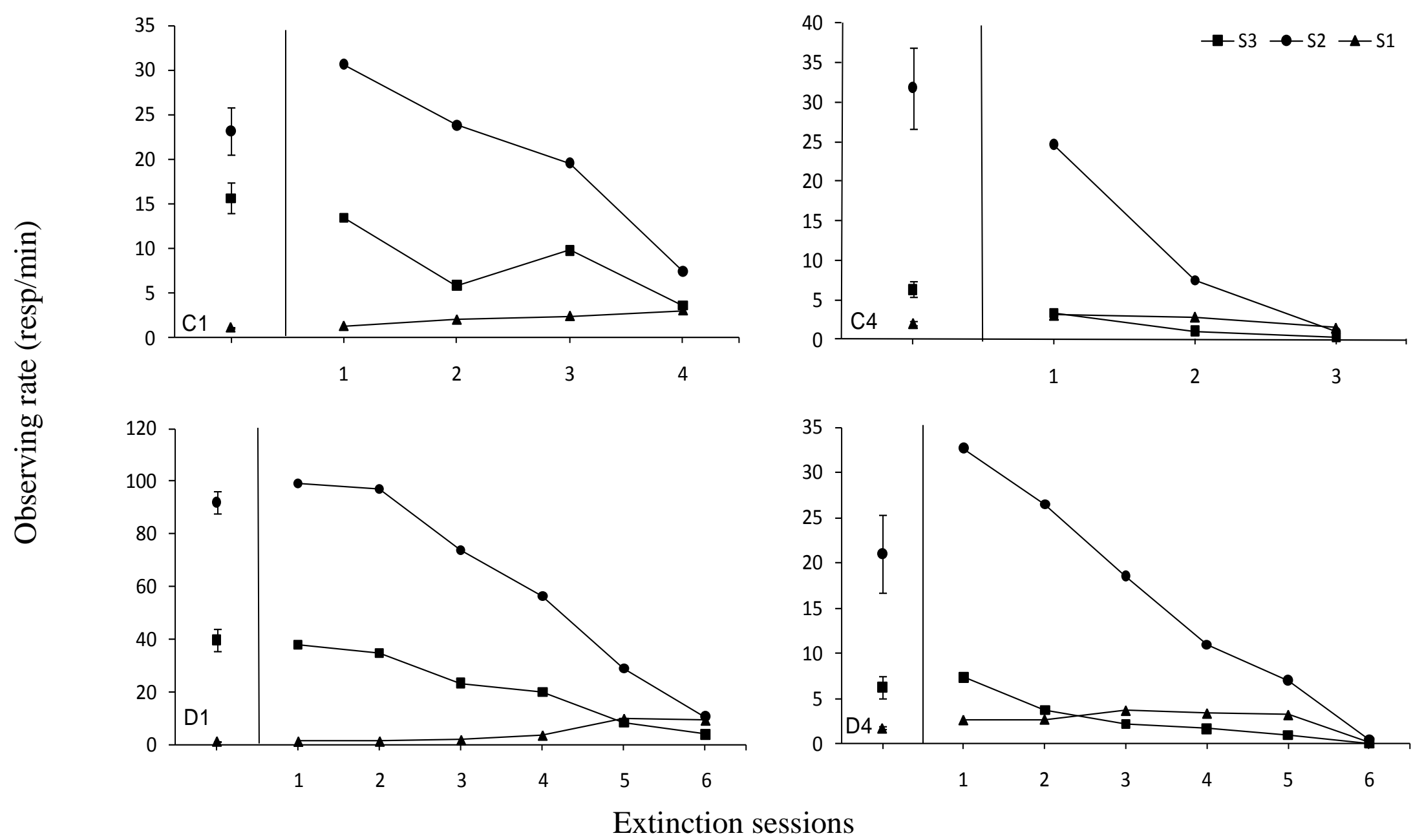

Figure 3. In the left panel, the average absolute observing rate (resp/min) during the last six baseline sessions is presented across the S3 link (filled squares), S2 link (filled circles) and S1 link (filled triangles). Error bars are presented as standard deviation, and in some cases were too small to be evident in the figure. In the right panel the absolute observing rate is presented for each link across each extinction session. The subject number is located in the lower left corner of each set of graphs. 

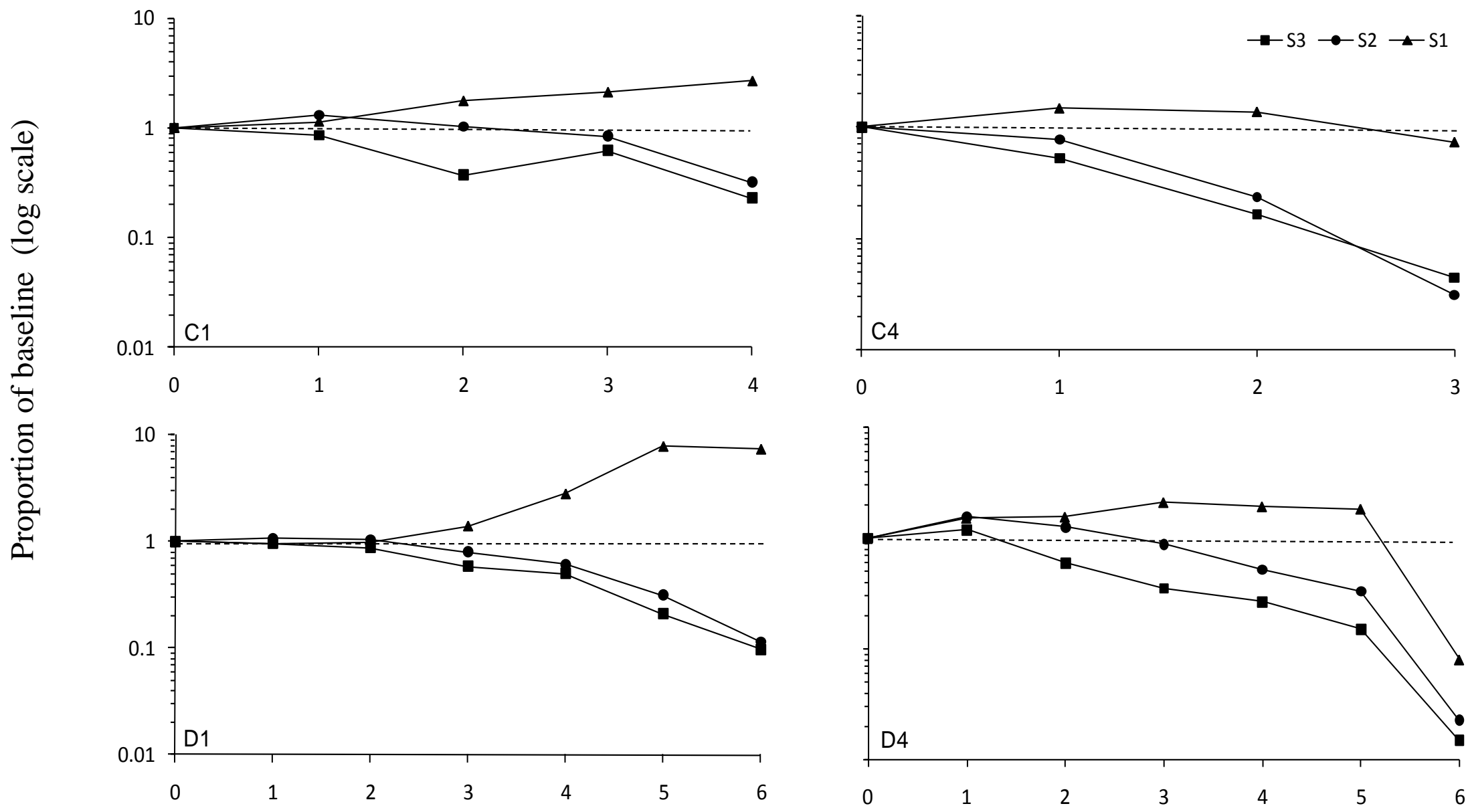

\section{Extinction sessions}

Figure 4. Observing rate (resp/min) during extinction sessions across the S3 link (filled squares), S2 link (filled circles) and S1 link (filled triangles) as a proportion of the last six sessions of baseline performance on a logarithmic y-axis for each subject. The subject number is located in the lower left corner of each graph. 
As a quantitative assessment of the change in observing rates due to the removal of food delivery, each function in Figure 4 was fitted to a line using a linear regression. The slope and fit $\left(r^{2}\right.$ value $)$ from the linear regression for individual subjects can be found in Table 2.

Table 2. The slopes and r-squared values from a linear regression analysis on proportion of observing rates during extinction and prefeeding sessions relative to the last six baseline sessions for individual subjects.

\begin{tabular}{|c|c|c|c|c|}
\hline Subject: & C1 & $\mathrm{C4}$ & D1 & D4 \\
\hline S3 extinction & $-0.17(0.75)$ & $-0.32(0.94)$ & $-0.16(0.96)$ & $-0.19(0.88)$ \\
\hline S2 extinction & $-0.18(0.62)$ & $-0.34(0.96)$ & $-0.16(0.88)$ & $-0.21(0.77)$ \\
\hline S1 extinction & $+0.43(0.97)$ & $-0.09(0.11)$ & $+1.23(0.75)$ & $-0.06(0.03)$ \\
\hline S3 prefeeding & $-0.26(0.89)$ & $-0.48(0.96)$ & $-0.28(0.99)$ & $-0.09(0.82)$ \\
\hline S2 prefeeding & $-0.24(0.91)$ & $-0.49(0.99)$ & $-0.28(0.95)$ & $-0.09(0.70)$ \\
\hline S1 prefeeding & $-0.09(0.70)$ & $-0.29(0.44)$ & $+0.21(0.94)$ & $+0.02(0.17)$ \\
\hline
\end{tabular}


A relatively steeper slope (i.e., a larger negative number) would indicate a greater decline in observing rates across extinction sessions. The decrease in observing rates for the production of the initial- and middle-link stimuli was approximately the same for individual subjects. The average slope for the initial-link and middle-link functions from Figure 4 was -0.21 and -0.22 , respectively. The average fit for the initial-link $\left(r^{2}=0.88\right)$ and middle-link functions $\left(r^{2}=0.81\right)$ was good, however, the average fit for the terminal-link function $\left(r^{2}=0.47\right)$ was poor with an average slope of +0.38 . This poor average fit is a reflection of the functions for subjects $\mathrm{C} 4$ and D4 because observing rates initially increased and then decreased by the last extinction session. Overall, the visual and quantitative analysis suggest that observing of the terminal-link stimulus proportionally decreased the least across extinction sessions and resulted in functions that produced a relatively small negative slope or positive slope. The quantitative assessment provides evidence that the overall decline in observing rates within the initial and middle links was practically equivalent.

\section{Prefeeding}

The results from effects of prefeeding on observing rates across each link were mostly consistent with effects of extinction on observing rates. Figure 5 shows effects of prefeeding on absolute observing rates relative to the average performance across the last six baseline sessions and Figure 6 shows effects of prefeeding across each prefeeding session as a proportion of baseline performance. As seen in Figure 6, the observing rate during the terminal link slightly increased (subject D1), increased and then decreased (subjects C4 and D4) or slightly decreased (subject C1) relative to baseline. The proportional decrease in observing of the terminal-link stimulus across all prefeeding sessions for each subject was less than that found with observing of the initial- or middle-link stimulus. The pattern of decline in the observing rate between 

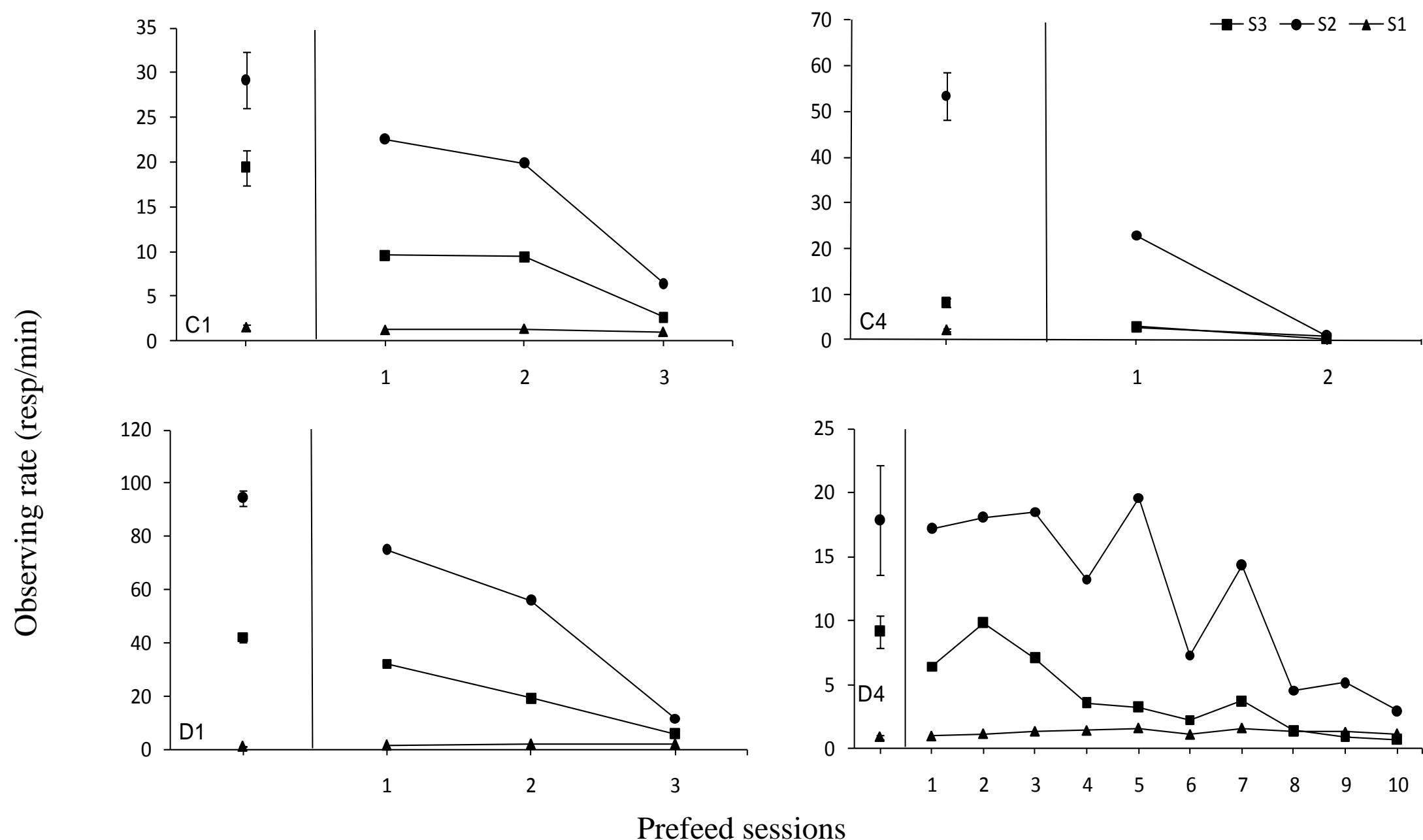

Figure 5. In the left panel, the average absolute observing rate (resp/min) during the last six baseline sessions is presented across the S3 link (filled squares), S2 link (filled circles) and S1 link (filled triangles). Error bars are presented as standard deviation, and in some cases were too small to be evident in the figure. In the right panel the absolute observing rate is presented for each link across each prefeeding session. The subject number is located in the lower left corner of each set of graphs. 

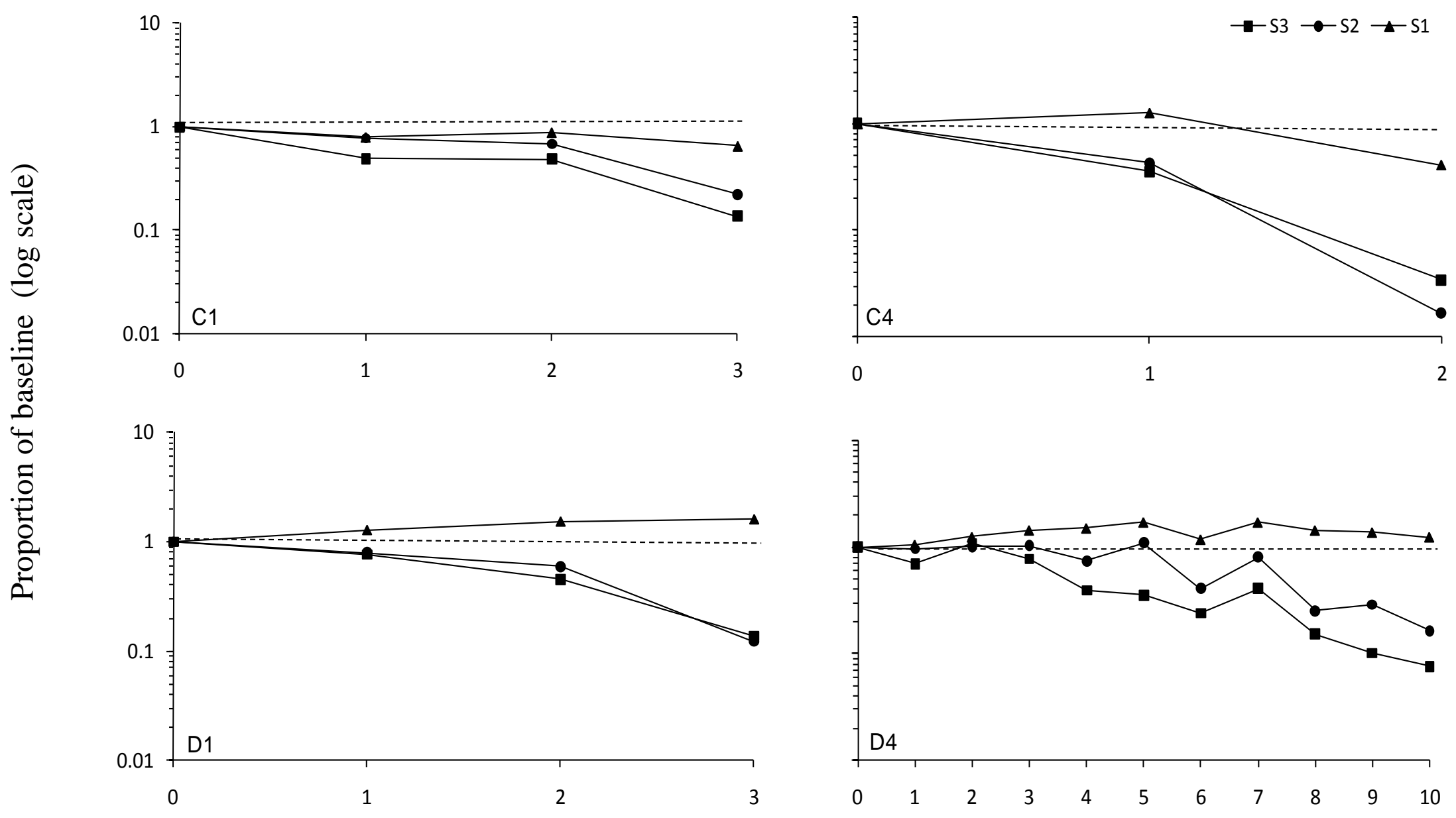

Prefeed sessions

Figure 6. Observing rate (resp/min) during prefeeding sessions across the S3 link (filled squares), S2 link (filled circles) and S1 link (filled triangles) as a proportion of the last six sessions of baseline performance on a logarithmic $y$-axis for each subject. The subject number is located in the lower left corner of each graph. 
initial- and middle-link stimuli across prefeeding sessions for each subject appeared to be quite similar except for subject D4. Observing for subject D4 decreased below baseline levels first during the initial link relative to the middle link.

The average slope and fit for the initial- and middle-link functions found in Figure 6 were $-0.28\left(r^{2}=0.92\right)$ and $-0.28\left(r^{2}=0.89\right)$, respectively, and were representative of individual subjects, as seen in Table 2. Thus, the overall proportional decline in observing rates was the same for the initial and middle links, while the average slope for the terminal-link functions was $-0.04\left(r^{2}=0.56\right)$. The relatively poor average fit was again a reflection of observing rates increasing and then decreasing across prefeeding sessions for subjects C4 and D4 (see Table 2).

Overall, these results were similar to effects of extinction on observing rates in that production of the terminal-link stimulus proportionally decreased the least relative to the middle- and initiallink stimuli. The proportional decline in observing rates during the middle and initial links was approximately the same across subjects.

\section{Discussion}

The typical measure of conditioned reinforcement in chain schedules is the response rate within each link of the chain. This measure is confounded because the same response results in both conditioned and primary reinforcement. In the present experiment, an observing contingency was utilized to assess the conditioned-reinforcing value of chain stimuli. Observing of stimuli correlated with a three-link chain schedule was established under conditions in which food was presented independent of a required response. Thus, an observing response that did not alter the rate of food delivery was maintained by the sole production of chain stimuli. These findings indicate conditioned-reinforcing properties of stimuli correlated with links of a chain schedule. The distribution of baseline observing was differential across the three links. The 
highest observing rate was found within the middle link, followed by the initial link and the lowest observing rate was found within the terminal link. This pattern of observing across the three links was not consistent with predictions based on the delay-reduction hypothesis of conditioned reinforcement. This inconsistency may be qualified by direct and indirect evidence suggesting certain superstitious patterns of behavior may have competed with observing within the terminal link.

\section{Baseline Observing}

The delay-reduction hypothesis suggests that a stimulus that signals a reduction in time to food, relative to the previous stimulus context, should be a conditioned reinforcer (Fantino, 1977). For three-link chain schedules with links of equal duration, only the terminal-link stimulus signals an average reduction in time to food and therefore should maintain the highest rate of observing. Observing for three chain/serial stimuli in previous experiments (e.g., Hendry \& Dillow, 1966; Kendall, 1972; Branch, 1975) indicate that observing rates were greater in the middle link relative to the terminal link under response-dependent food schedules. Some authors (e.g., Kendall, 1972) have reasoned that response competition between food-key responding and observing resulted in the decreased rate of observing within the terminal link. In the present experiment, response-independent food delivery was used in an attempt to isolate the relation between stimuli correlated with links of a chain and food delivery (i.e., isolate conditioned reinforcement effects) and also decrease the likelihood of response competition. Despite this procedural change to isolate conditioned reinforcement effects, observing rates were greatest for the production of the middle-link stimulus, then initial-link stimulus, and lowest for the production of the terminal-link stimulus. 
An explanation for the rate of observing found in the terminal link is related to the baseline schedule of food delivery. The observing training regime in the present study consisted of various conditions in which response-independent food was paired with schedule-correlated stimuli. Under these conditions, there is the possibility for certain superstitious patterns of behavior (Skinner, 1948) to develop. In the presence of the terminal-link stimulus, which is most predictive of food delivery, certain patterns of behavior increased in frequency as noted via video-monitoring equipment. Behavior in the presence of the terminal-link stimulus such as pacing in front of the key panel or pecking the corner of the operant-conditioning chamber may have been maintained by adventitious reinforcement (i.e., incidental reinforcement of behavior via a close temporal relation with food presentation). Staddon and Simmelhag (1971) observed behavior of pigeons under response-independent FT 12-s schedules and VT 8-s schedules. The behavior prior to food delivery under both conditions was found to be either "pecking or a stereotyped pacing activity obviously related to it" (Staddon, 1992, p. 272). The patterns of behavior observed by Staddon and Simmelhag were similar with those found in the present study, although they were opposed to adventitious reinforcement as the maintaining process (see General Discussion). In any case, the superstitious behavior in the present experiment may have been under strong stimulus control via production of the terminal stimulus, and thus, competed with observing in the terminal link.

The superstitious behavior was not apt for systematic analysis by the behavioral measurement techniques of the present experiment. Perhaps motion sensors or a force-plate actometer would have been a useful means to measure the unrecorded behavior. Despite the limitation of indirect evidence of observing competing with superstitious behavior, response competition has been reported in a number of previous observing experiments (e.g., Kendall, 
1965; Hendry \& Dillow, 1966; Kendall, 1972; Case and Fantino, 1981; Shahan, 2002). The development of superstitious behavior that competed with observing was not anticipated in the present study. The response-independent food schedule was used to decrease the likelihood of response competition that has been suggested in previous studies with response-dependent food schedules. Although the results were not anticipated, there are a number of examples (Skinner, 1948; Neuringer, 1970; Staddon, \& Simmelhag, 1971) of the development of superstitious patterns of behavior with pigeons as subjects. Thus, the low rates of observing within the terminal link, although contrary to predictions based on the delay-reduction hypothesis, may be a result of behavior not under explicit experimental control.

There was an attempt to disrupt the supersitious behavior during the initial baseline condition via increasing the minimum interval length while holding the food-delivery rate constant. For example, for subject D1 the VT interval distribution was changed from $10-100 \mathrm{~s}$ to $30-80 \mathrm{~s}$, under the conception that the shorter intervals may have been more conducive to maintaining the superstitious pattern of behavior. Little change in observing was evident as a result of this manipulation. Future manipulations could include further decreasing the rate of food delivery, or providing additional chain stimuli (e.g., have six links instead of three). The latter manipulation appeared useful for Hendry and Dillow (1966) in Experiment 3 for preventing the decline in observing of a terminal stimulus correlated with the last minute of an FI 6-min food schedule.

\section{Extinction and Prefeeding}

The extinction condition was conducted in order to test the classical-conditioning interpretation of chain-schedule performance, while the prefeeding condition was conducted as a test of generality to an alternative disruptive condition. The classical-conditioning account 
would hold that observing in the terminal link should decrease first, followed by decreases in the middle link, and eventual decreases in the initial link. This pattern of extinction would be due to disruption of first-order conditioning between the pairing of the terminal-link stimulus and food, followed by the disruption of higher-order conditioning between the pairing of the middle- and terminal link stimuli, and then disruption of the pairing between initial- and middle-link stimuli. The results from the present experiment indicate that the traditional account of chain-schedule performance was generally not supported under extinction and prefeeding conditions.

Although the terminal-link stimulus was produced the least during baseline sessions, observing in the terminal link during extinction proportionally decreased the least relative to observing in the other two links across all extinction sessions. These results are generally consistent with findings from Nevin, Mandell, and Yarensky (1981) in that terminal link responding proportionally decreased the least relative to initial-link responding under two-link RI chain schedules of reinforcement during prefeeding and alternative-reinforcement conditions. Thus, the terminal-link stimulus may have had the greatest conditioned-reinforcing value, but was only evident when tested in a resistance-to-change context (i.e., effects of extinction and prefeeding on observing of the terminal-link stimulus were consistent). The fact that observing of the terminal-link stimulus did not decrease prior to decreases in observing of the other links is evidence against the classical-conditioning account of chain-schedule performance, but there are caveats.

There is the possibility that baseline observing rates in the terminal link were too low to see further decreases due to an experimental manipulation. The notion of a floor effect is supported by the fact that observing only decreased below baseline levels in the terminal link by the last extinction session for one of four subjects and two of four by the last prefeeding session. 
In contrast, it could also be the case that the criterion for ending the extinction condition was not sufficient to capture the full effect (i.e., observing may have decreased below baseline levels with more extinction sessions). Future replications with extended extinction and prefeeding sessions could resolve this issue.

It is important to note that observing of the terminal-link stimulus increased across sessions for each subject during extinction. The proportional change in observing within the extinction condition for subjects D1, C1, and D4 was at least a two-fold increase in observing. The proportional increase in observing during the prefeeding condition was relatively small compared to the extinction condition and not as robust across subjects. The cause of increased observing in the extinction condition is not evident. Based on the contention that superstitious behavior may have been competing with observing of the terminal-link stimulus at baseline, the superstitious behavior may have extinguished to some extent when food was removed. Thus, competition with other behavior may have decreased, which increased the opportunity to observe the terminal-link stimulus. This tentative conclusion still does not explain why there was a selective increase in observing of the terminal-link stimulus when the reinforcer for maintaining the first-order relation was no longer present.

Initial- and middle-link performance under extinction and prefeeding conditions provided a more clear assessment of a backward transmission of reinforcer value in chain schedules. Visual analysis suggests that observing of the initial-link stimulus decreased first relative to observing of the middle-link stimulus for two of four subjects (C1 and D4) during the extinction condition and for one of four subjects (D4) during the prefeeding condition, indicative of a forward pattern of extinction for those subjects. For all other subjects in both conditions, the pattern of observing across sessions visually appeared to be the same in the initial and middle 
links. Thus, in no case was a backward pattern of extinction observed across initial and middle links.

When examining the overall decline in observing across sessions under extinction and prefeeding conditions, the change in the proportion of observing rates was nearly identical between the initial and middle links as quantified by a linear regression. If it is the case that additional links at the start of a chain have diminishing value "because each additional step of higher order conditioning attenuates the level of value transmission” (Williams, Ploog, \& Bell, 1995, p. 104), then the rate of decline would likely be differential across the initial and middle links. Instead, the linear decline in observing of the first two link stimuli was almost identical. The overall findings based on observing within the initial and middle links during extinction and prefeeding replicate extinction results from Bell and McDevitt (2007). They examined the pattern of extinction under response-dependent three-link chain schedules and found either no difference in the rate of extinction in the initial relative to the middle link or they found a forward pattern of extinction.

\section{Conclusion}

In various experimental contexts, there has been evidence that supports (Williams, 1997; 1999) and does not support (Nevin, Mandell, \& Yarensky, 1981; Bell, \& McDevitt, 2007) a backward transmission of reinforcer value in chain schedules. Three key results indicate that the traditional interpretation of chain performance was not supported in the present study. First, observing decreased the least within the terminal link during extinction and prefeeding conditions. Second, a consistent backward pattern of extinction across links did not emerge across subjects. Third, similar decreases in the rate of observing in the initial and middle links were evident across subjects within extinction and prefeeding conditions. 
Royalty, Williams, and Fantino (1987) raised the question as to whether the relatively brief stimulus presentations in observing preparations are functionally the same as strict chainschedule arrangements where the stimuli are present for longer periods of time without intervening changes in the stimulus context (i.e., the tandem condition within an observing procedure). It is ultimately possible that the relations between chain stimuli (first-order and higher-order conditioning) were disrupted or entailed a more complex stimulus arrangement via the introduction of the tandem stimulus. The alternating stimulus conditions within each link may have negated the likelihood of observing a backward pattern of extinction.

Certain features of chain schedules such as constant stimulus conditions within each link, and consistent pairings of the chain stimuli were not part of the present experimental arrangement. In early training, sessions began with forced exposure to the chain stimuli for 10 trials prior to implementing the observing contingency. When the forced exposures were removed later in training, there was no evidence that observing changed in any systematic fashion across subjects, however, training sessions were not conducted until stable performance prior to removing the forced exposures. Another aspect different from typical chain schedules is the fact that the tandem stimulus was present during all link transitions when the observing contingency was implemented. Thus, there was never a direct/immediate pairing of link stimuli under observing conditions. Future research could entail investigating effects of direct pairings of link stimuli on observing, but ultimately the number of pairings would be under the control of the behavior of the subject.

The present experiment was carried out under the assumption that the observing contingency may be used as a behavioral sensor to detect the conditioned-reinforcing value of chain stimuli and that the above mentioned features of chain schedules were not essential to 
establish observing. Observing was maintained by the production of chain stimuli, but whether one or all of the stimuli were critical for the maintenance of observing was not clearly addressed. Predictions based on the delay-reduction hypothesis would support only the terminal stimulus serving as a conditioned reinforcer because it is the only stimulus that signaled an average reduction in time to food relative to the tandem condition. Despite the suggestion by Hendry and Dillow (1966) that all stimuli within a chain may have conditioned-reinforcing properties, there has been experimental evidence to the contrary. Dinsmoor, Lee, and Brown (1986) examined autoshaped pecking in which four colors were consistently presented prior to food delivery in a chain sequence with each link averaging $30 \mathrm{~s}$ in duration. In the critical experimental manipulation, key pecks could replace each stimulus with a consistent substitute stimulus for a period of 1 or $5 \mathrm{~s}$. Key pecks increased in the presence of the first stimulus and decreased in the presence of the terminal stimulus relative to baseline performance. These results indicate that the initial stimulus had aversive properties because it maintained an escape response. These findings are also consistent with results from previous observing studies involving serial/chain stimuli (Kendall, 1972; Auge, 1977; Escobar \& Bruner, 2009). The conditioned-reinforcing value of a stimulus appears to be best predicated on the time the stimulus signals relative to primary reinforcement (i.e., delay reduction).

In the present study, a response was maintained by the production of chain stimuli correlated with the availability of food, despite the fact that no defined response was required for the delivery of food. The distribution of observing responses in baseline conditions was not consistent with the delay-reduction hypothesis, but was likely a result of contingencies not under explicit experimental control. A backward transmission of reinforcer value was not found in the present study for at least two reasons. First, the observing procedure may not be apt to examine 
conditioned reinforcement in chain schedules as suggested by Williams, Royalty and Fantino (1987). Second, the classical-conditioning account of conditioned reinforcement in chain schedules may not be the most parsimonious explanation. Higher-order conditioning in chain schedules is typically suggested or implied, while delay reduction has been demonstrated to be predictive of a wide variety of experimental arrangements involving conditioned reinforcement (Fantino, 1977). The present experiment was an attempt to isolate the reinforcing effects of chain stimuli and assess predictions based on higher-order conditioning. Although no experimental evidence was supportive of the classical-conditioning hypothesis, the present results are not decisive concerning the relevance of the classical-conditioning interpretation of chain schedule performance.

\section{Experiment 2}

There have been a number of studies examining effects of stimulant drugs on responding maintained by a conditioned reinforcer. Those studies primarily consisted of testing conditioned reinforcement effects under extinction, second-order schedules, or by establishing a new response (see Beninger \& Ranaldi, 1994 for a review). The general finding is that stimulant drugs enhance the efficacy of conditioned reinforcers. The observing procedure is considered to be the optimal test of conditioned reinforcement (Dinsmoor, 1983). Although administration of the stimulant drug nicotine has resulted in robust increases in observing relative to saline (Raiff $\&$ Dallery, 2006; 2008), effects of $d$-amp on observing have not resulted in clear increases in observing (Clark, 1969; Branch, 1975). In Experiment 2, effects of $d$-amp were assessed under the same experimental arrangements as Experiment 1 to determine if observing of chain stimuli could be enhanced by the administration of a stimulant drug. After $d$-amp testing, effects of 
morphine were assessed to determine if a drug outside the stimulant drug class may also increase observing of chain stimuli (i.e., a negative control).

\section{Subjects \& Apparatus}

\section{Method}

The same four male Carneau pigeons served as subjects and were maintained under the same conditions as Experiment 1. The same apparatus was used as in Experiment 1.

\section{Drug Procedure}

For all subjects, Experiment 2 immediately followed Experiment 1 and the same baseline schedule was used. Drug testing occurred every third day, with performance from the previous session serving as control. Control sessions were judged stable if falling within a range (judged by visual analysis) of the previous stable baseline conditions in Experiment 1. Before administration of $d$-amp, saline (vehicle) was administered into the breast muscle (intramuscular, i.m.) of the pigeons. The location of every injection alternated between the left and right breast muscle. $d$-Amphetamine sulfate salt was dissolved in a $0.9 \%$ saline solution $(1 \mathrm{mg} / \mathrm{ml})$ and had an injection volume of $1.0 \mathrm{ml} / \mathrm{kg}$. The doses tested were $0.3,1.0,1.7$, and $3.0 \mathrm{mg} / \mathrm{kg}$. After each injection, the subject was placed in a dark operant-conditioning chamber for 5 min and then the session started. Dose determinations were obtained in an ascending and then descending dose order for D1 and C4 and were reversed for $\mathrm{C} 1$ and D4. Effects of each dose were determined at least twice and additional doses were tested depending upon variability in effects of the drug. After the $d$-amp testing phase, morphine testing began. Morphine was administered into the breast muscle (i.m.) of the pigeons. Morphine sulfate was dissolved in a $0.9 \%$ saline solution $(1 \mathrm{mg} / \mathrm{ml})$ and had an injection volume of $1.0 \mathrm{ml} / \mathrm{kg}$. The doses tested were 1.0, 3.0 and 5.6 $\mathrm{mg} / \mathrm{kg}$. After each injection, the subject was placed in a dark operant-conditioning chamber for 5 
min and then the session started. The number and order of dose determinations was the same as under the $d$-amp procedure.

\section{Data Analysis}

The average observing rate producing each schedule-correlated stimulus during saline tests were compared to each dose of $d$-amp and morphine within and across subjects. The observing rates during tests of $d$-amp and morphine doses as a proportion of the saline observing rates were also compared within and across subjects. In some cases (see Sanger \& Blackman, 1976), effects of drugs on behavior may be related to the baseline rate of behavior. That is, response rates tend to increase after $d$-amp administration when baseline rates are relatively low and response rates tend to decrease after $d$-amp administration when baseline rates are relatively high. An analysis of rate dependency was conducted by plotting effects of each dose of $d$-amp as a log proportion of saline as a function of log saline observing rates to determine if effects of $d$-amp administration were related to saline observing rates. Rate-dependent drug effects would be evident by low saline observing rates increasing and high saline observing rates decreasing after drug administration. The best-fit line was plotted by means of linear regression. A separate ratedependency analysis was also conducted for effects of morphine.

\section{Results}

The absolute rate of observing after administration of saline or $d$-amp $(0.3-3.0 \mathrm{mg} / \mathrm{kg})$ can be found in Figure 7. With regard to observing within the initial (S3) and middle (S2) links, there was a general dose-dependent decrease in observing rates relative to saline. Results from subjects C4 and D4, however, show a slight exception to this pattern. Administration of 1.0 $\mathrm{mg} / \mathrm{kg} d$-amp resulted in a small increase in observing for the production of the initial-link stimulus for subjects C4 and D4. For subject D4, there was also some shift in the baseline observing rates as evident by the large error bars around the mean for saline. 
Effects of $d$-amp administration on observing within the terminal link (S1) show a general increase in observing at moderate doses $(1.0$ and $1.7 \mathrm{mg} / \mathrm{kg})$ relative to saline across subjects. The increases in observing found within the terminal link are more evident in Figure 8, which shows proportional change relative to saline. The average observing rate increases were at least two-fold for subjects $\mathrm{C} 1, \mathrm{C} 4$, and $\mathrm{D} 1$ after administration of $1.7 \mathrm{mg} / \mathrm{kg} d$-amp. On average, increases in observing were found for each subject within the terminal link at moderate doses, but error bars for subjects $\mathrm{C} 1$ and $\mathrm{D} 4$ were still within the range of performance after saline administration (see Figure 8). A dose of $5.6 \mathrm{mg} / \mathrm{kg} d$-amp was tested for subject C4 to determine if observing would decrease at a higher dose within the terminal link. Observing rates remained high relative to saline after $5.6 \mathrm{mg} / \mathrm{kg} d$-amp administration, however, subject $\mathrm{C} 4$ did not gain weight during test sessions and grain was found on the floor of the chamber at the end of test sessions (i.e., subject $\mathrm{C} 4$ did not consume the grain at this dose). 


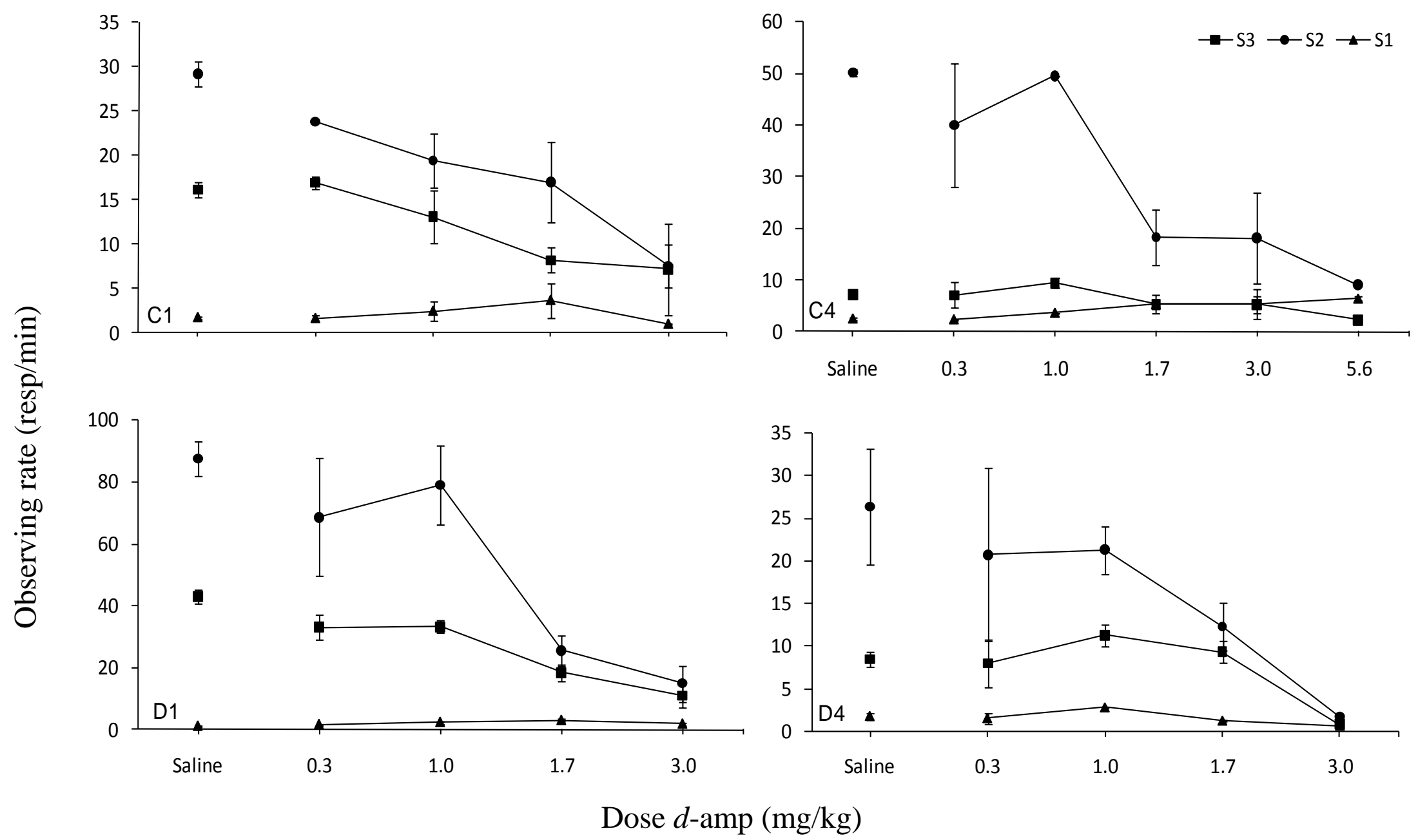

Figure 7. Average absolute observing rate (resp/min) after administration of $d$-amp across the S3 link (filled squares), S2 link (filled circles) and S1 link (filled triangles) at saline and each dose of $d$-amp for each subject. The subject number is located in the lower left corner of each graph. Error bars are standard error of the mean. Notice scaling differences on the y-axis. 

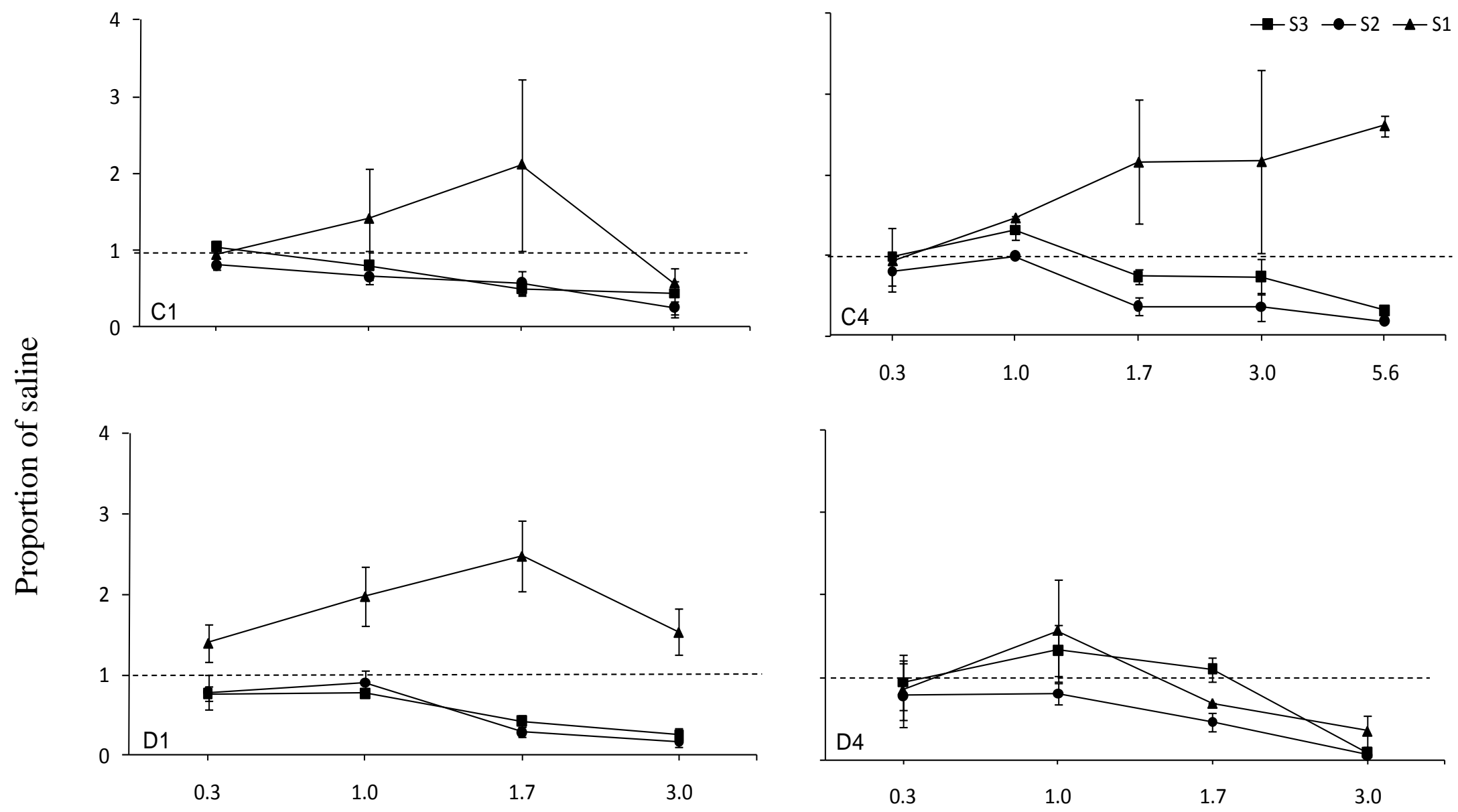

\section{Dose $d$-amp $(\mathrm{mg} / \mathrm{kg})$}

Figure 8. Average observing rate (resp/min) after administration of $d$-amp across the S3 link (filled squares), S2 link (filled circles) and S1 link (filled triangles) as a proportion of observing after saline administration for each subject. The subject number is located in the lower left corner of each graph. Error bars are standard error of the mean. 
Effects of each dose of $d$-amp as a log proportion of saline were graphed as a function of $\log$ saline observing rates (see Figure 9) to determine if effects of $d$-amp administration were related to saline observing rates (i.e., a rate-dependency analysis). Each panel in Figure 9 represents a particular dose (bottom-left corner) and each point represents the average observing rate within a particular link for each subject. Points above the dotted line indicate observing rate increases relative to saline and points below the dotted indicate observing rate decreases relative to saline. Of particular interest are the doses of 1.0 and $1.7 \mathrm{mg} / \mathrm{kg} d$-amp (top right and bottom left panels, respectively). The highest observing rates following saline administration (found within the middle link symbolized by circles) stayed the same or decreased after $d$-amp administration. The lowest saline observing rates (found within the terminal link symbolized by triangles) increased after $d$-amp administration in seven of eight cases. Within the initial link (symbolized by squares), the relatively low saline observing rates within subject increased in three of four cases and the relatively high saline observing rates within subject decreased. At the lowest dose of $d$-amp tested $(0.3 \mathrm{mg} / \mathrm{kg})$, there was little change in observing rates relative to saline observing rates. At the highest dose of $d$-amp tested in each subject ( $3.0 \mathrm{mg} / \mathrm{kg})$, there was a general decrease in observing, but still in a pattern consistent with rate dependency. 

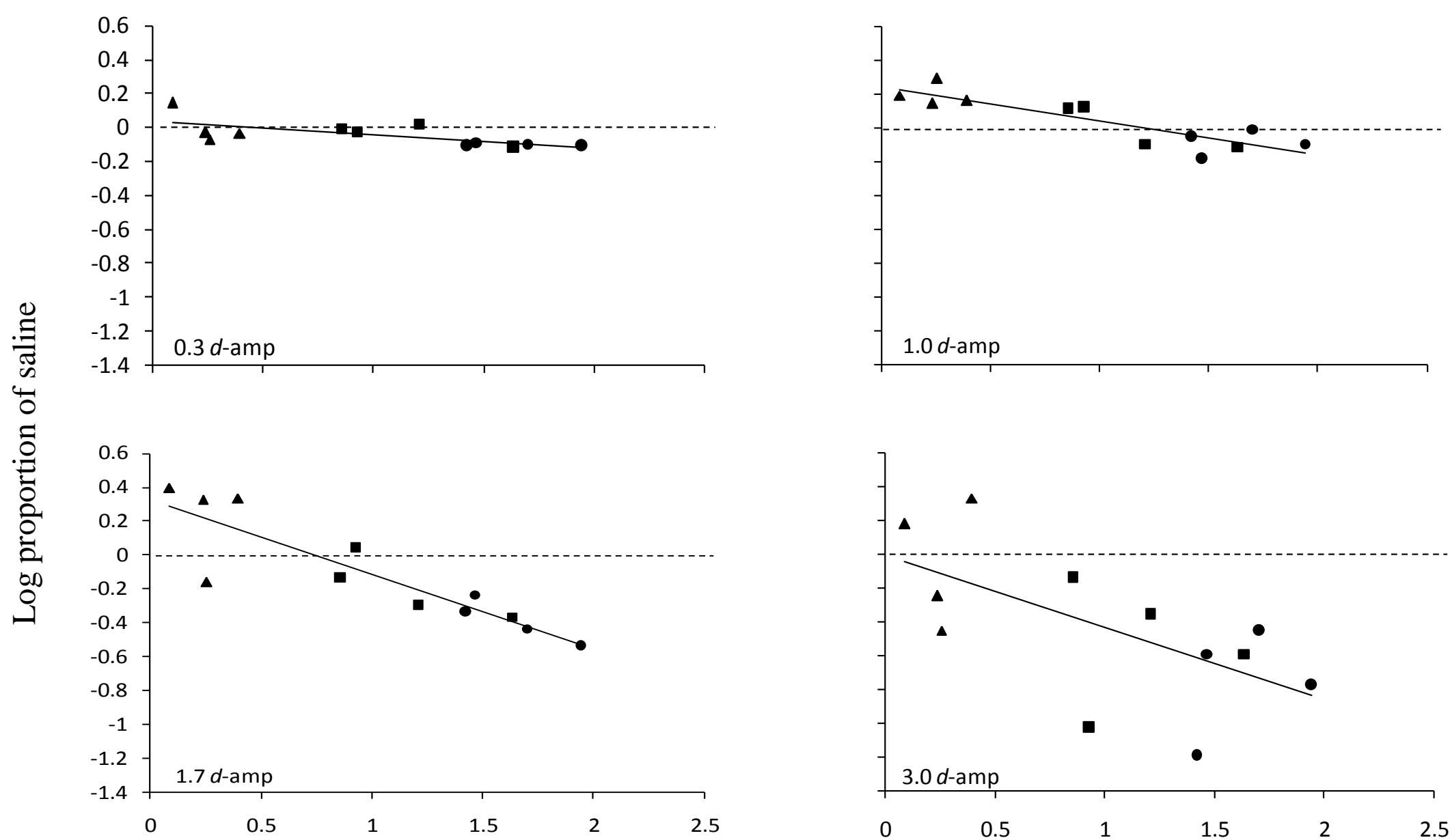

Log saline observing rate

Figure 9. Rate-dependency analysis for each dose of $d$-amp (lower left corner within each panel). Log observing rates after administration of $d$-amp within the S3 link (filled squares), S2 link (filled circles) and S1 link (filled triangles) as a proportion of saline observing rates are graphed as a function of log saline observing rates for each subject. 
Figure 10 shows the absolute observing rates after morphine $(1.0-5.6 \mathrm{mg} / \mathrm{kg})$ and saline administration. Across subjects the findings were mostly consistent with effects of $d$-amp administration. Within the initial and middle links, there was a general dose-dependent decrease in observing rates. For subject $\mathrm{C} 4$, however, there was a slight increase in observing after administration of $1.0 \mathrm{mg} / \mathrm{kg}$ morphine in the initial link. Effects of morphine on observing within the terminal link show an increase in observing at the highest two doses for three of four subjects. Figure 11, which illustrates the proportional change relative to saline as a function of dose, magnifies the observing results within the terminal link. At 3.0 or $5.6 \mathrm{mg} / \mathrm{kg}$ morphine, observing rates increased relative to saline in three of four subjects. The rate-dependency analysis for morphine (see Figure 12) shows a similar dose-dependent effect as the results from $d$-amp administration. At the lowest dose tested $(1.0 \mathrm{mg} / \mathrm{kg}$ morphine $)$ observing rates did not change relative to saline. At the highest two doses tested (3.0 and $5.6 \mathrm{mg} / \mathrm{kg}$ morphine) relatively low saline observing rates tended to increase (except for subject D4) and relatively high saline observing rates tended to decrease. 

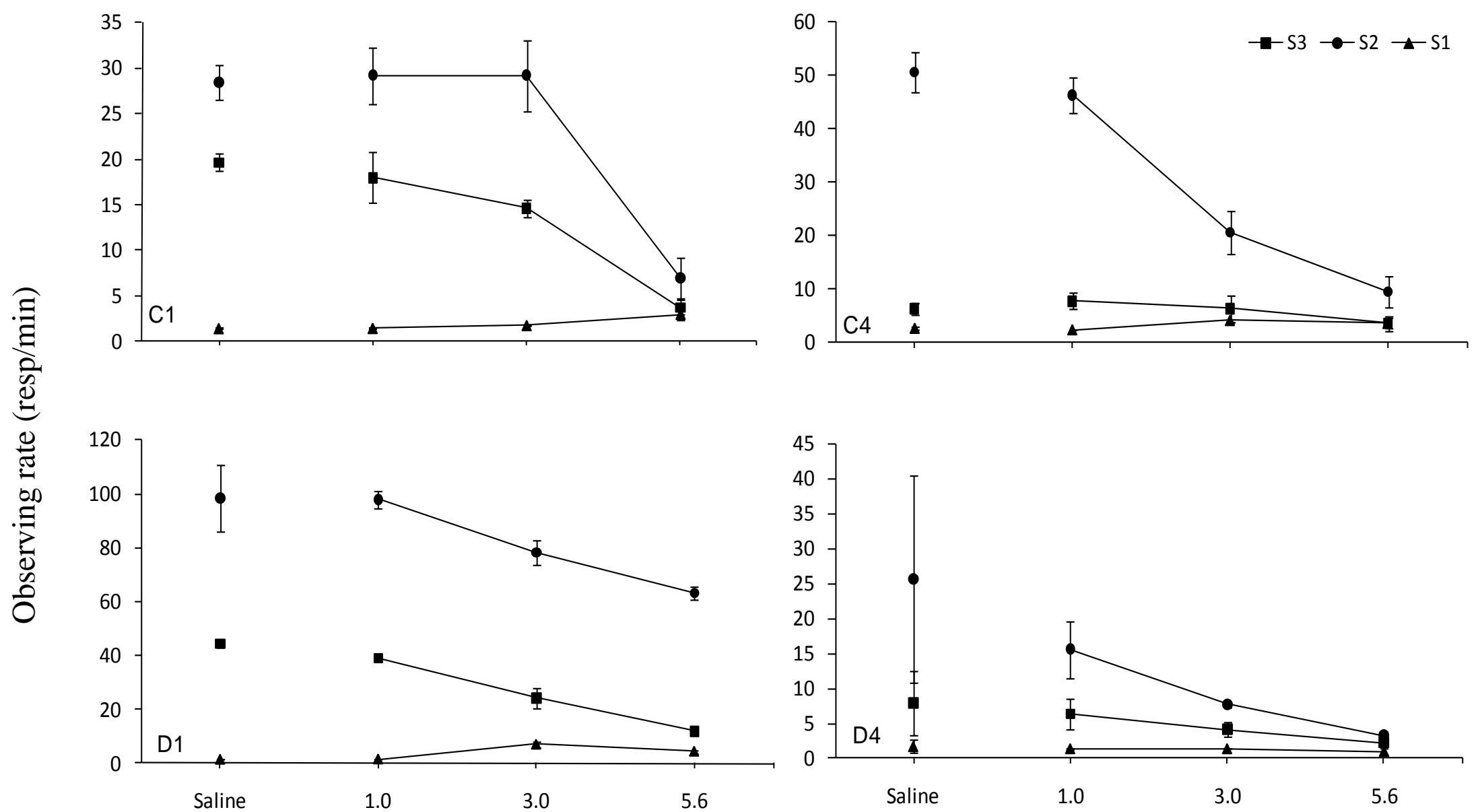

Dose morphine $(\mathrm{mg} / \mathrm{kg})$

Figure 10. Average absolute observing rate (resp/min) after administration of morphine across the S3 link (filled squares), S2 link (filled circles) and S1 link (filled triangles) at saline and each dose of morphine for each subject. The subject number is located in the lower left corner of each graph. Error bars are standard error of the mean. Notice scaling differences on the y-axis. 

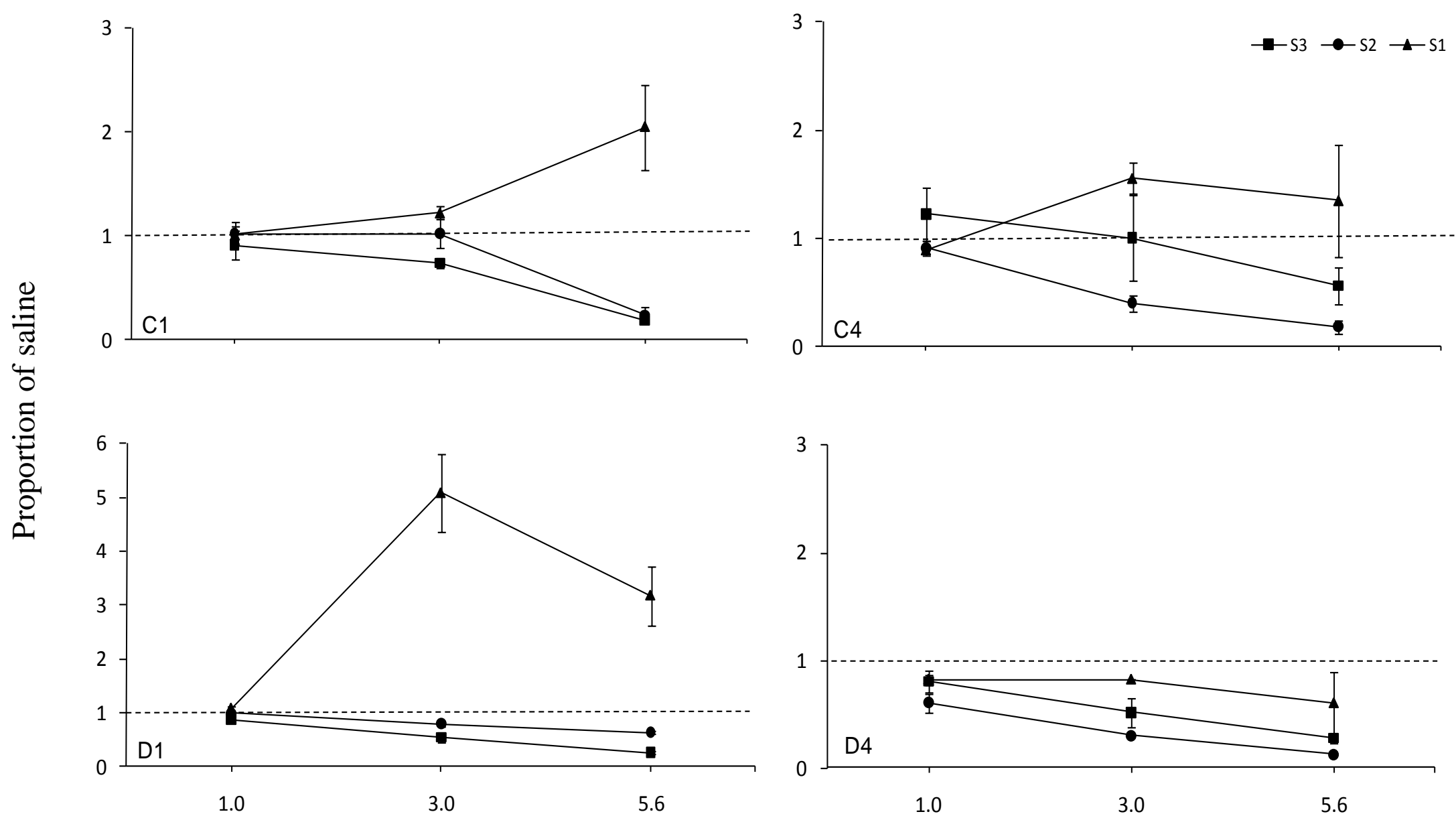

Dose morphine $(\mathrm{mg} / \mathrm{kg})$

Figure 11. Average observing rate (resp/min) after administration of morphine across the S3 link (filled squares), S2 link (filled circles) and S1 link (filled triangles) as a proportion of observing after saline administration for each subject. The subject number is located in the lower left corner of each graph. Error bars are standard error of the mean. Notice the change in scaling for subject D1. 

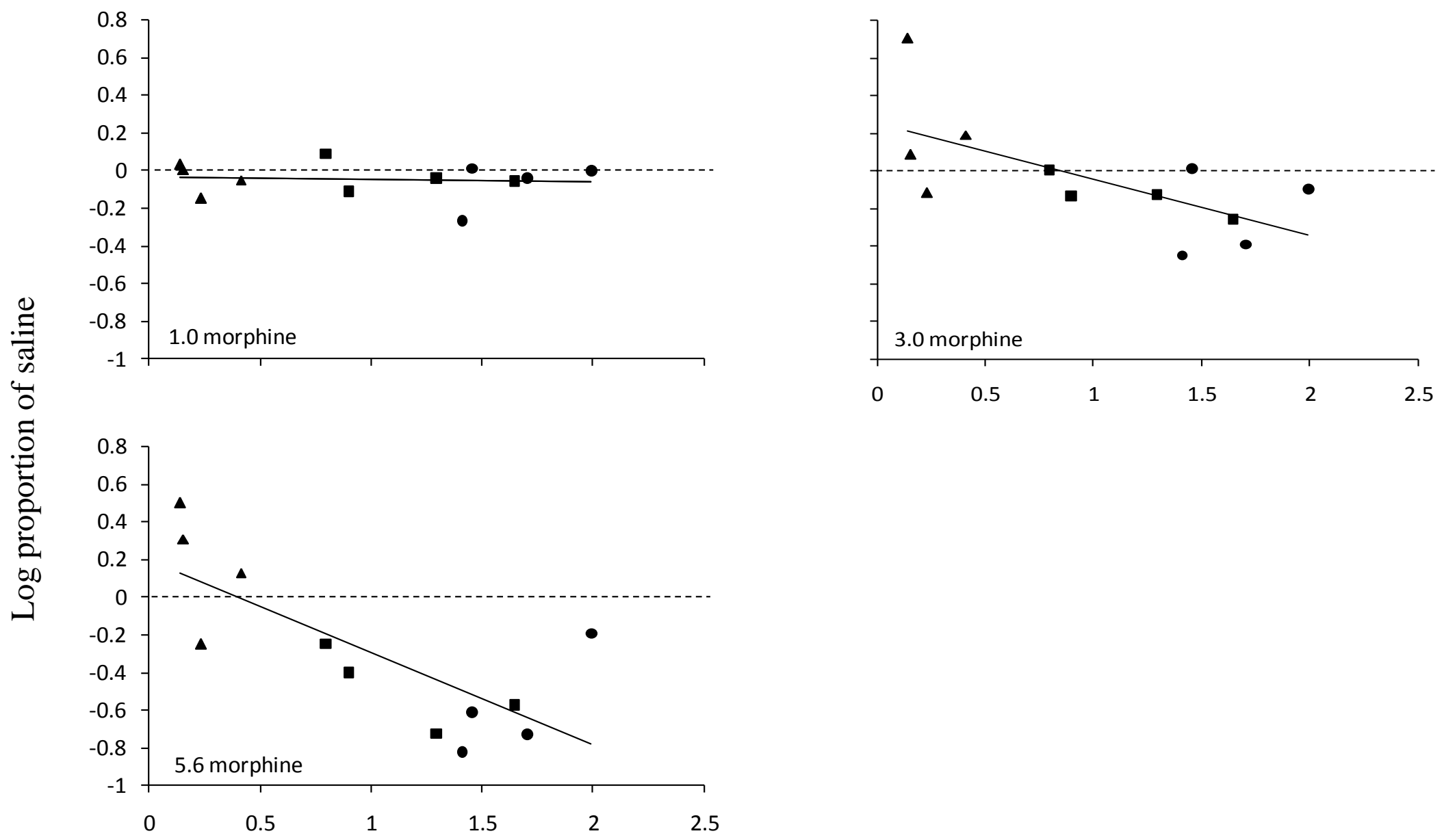

Log saline observing rate

Figure 12. Rate-dependency analysis for each dose of morphine (lower left corner within each panel). Log observing rates after administration of morphine within the S3 link (filled squares), S2 link (filled circles), and S1 link (filled triangles) as a proportion of saline observing rates are graphed as a function of log saline observing rates for each subject. 


\section{Discussion}

Some researchers (e.g., Hendry \& Dillow, 1966) have suggested that all chain stimuli may serve as conditioned reinforcers. In Experiment 1, observing was established for stimuli correlated with a three-link VT schedule of food delivery. These findings indicate conditionedreinforcing value of chain stimuli, although the link stimulus or stimuli that was critical for maintaining observing was not determined. Past research (Beninger \& Ranaldi, 1994) has indicated that stimulant drugs tend to increase the efficacy of conditioned reinforcers under extinction conditions and second-order schedules. In the present experiment, $d$-amp was administered in an attempt to replicate previous findings that stimulant drugs enhance conditioned-reinforcer efficacy under the arrangement of an observing procedure. Past research with nicotine (Raiff \& Dallery, 2006; 2008) has demonstrated enhanced observing relative to saline, but results from tests of $d$-amp (Clark, 1969; Branch, 1975) have not been as clear.

\section{Conditioned-Reinforcement Effect and d-Amp}

Administration of $d$-amp relative to saline generally resulted in dose-dependent decreases in observing within the initial and middle links across subjects (subjects C4 and D4 were a slight exception). Within the terminal link, administration of moderate doses of $d$-amp (1.0 and 1.7 $\mathrm{mg} / \mathrm{kg}$ ) resulted in clear increases in observing for two subjects (C4 and D1) and an increasing pattern of observing for the other two subjects ( $\mathrm{C} 1$ and $\mathrm{D} 4)$. For three of the four subjects, the increase in the average observing rate was at least two-fold at a moderate dose. Thus, the reliable finding across subjects was that certain doses of $d$-amp resulted in increases in the average rate of observing within the terminal link, and mostly decreases in observing within the initial and middle links. These results are consistent with predictions based on the delayreduction hypothesis of conditioned reinforcement. 
The delay-reduction hypothesis would hold that only the terminal-link stimulus signals an average reduction in time to food relative to the tandem condition. The initial-link stimulus signals an increase in the average time to food and the middle-link stimulus signals an equivalent average time to food relative to tandem conditions. If $d$-amp enhances the efficacy of conditioned reinforcers, then administration of $d$-amp should only increase observing of the terminal-link stimulus, which was the general finding across subjects. This result appears to be in contrast with findings from Branch (1975) in which observing rates stayed the same or decreased within the last third of an FI schedule after administration of $d$-amp. The reason behind the discrepancy in results is not apparent, but could be related to the different schedules of food delivery (independent vs. dependent) and the different pattern of baseline observing.

There has been experimental evidence suggesting that not all chain/serial stimuli have conditioned-reinforcing value (Kendall, 1972; Auge, 1977; Dinsmoor, Lee, \& Brown, 1986; Escobar \& Bruner, 2009), which supports the notion that only the production of the terminal-link stimulus would be enhanced. Although it was not established in the present set of experiments which stimulus or stimuli were critical for the maintenance of observing, the results based on $d$ amp testing are in agreement with the delay-reduction hypothesis of conditioned reinforcement. A conditioned reinforcement enhancement effect due to $d$-amp administration, however, is less likely when considering the rate-dependency analysis and effects of morphine.

Rate Dependency and d-Amp

There is a substantial literature within behavioral pharmacology (see Sanger \& Blackman, 1976 for a review) that pertains to the rate-dependent effects of drugs. It has been found within different pharmacological drug classes that low baseline rates tend to be increased and high baseline rates tend to be decreased after administration of certain drugs such as 
stimulants. The baseline of the present study was useful to assess rate dependency because a range of response rates was established within subject. Overall, high baseline rates of observing tended to decrease and relatively low rates of observing tended to increase after administration of 1.0 and $1.7 \mathrm{mg} / \mathrm{kg} d$-amp. Rate dependency may also provide a useful description of the slight increases in observing found within the initial links for subjects C4 and D4 at $1.0 \mathrm{mg} / \mathrm{kg} d$-amp. The initial-link saline observing rates were relatively low compared to observing found within the other two links for both subject C4 and D4.

Branch (1975) found that administration of certain doses of $d$-amp or chlorpromazine increased the lowest rates of observing found within the first third of an FI 120 and mostly decreased the highest rates of observing found within the middle third of the FI. Observing within the last third of the FI was moderate in rate, and decreased relative to saline. Although a rate-dependency analysis was not conducted, it was argued that the overall drug effects on observing were not rate dependent because the baseline rates within the last third of the FI were moderate only in absolute terms, but low in comparison. The ultimate conclusion by Branch was that observing in that particular experiment was a form of adjunctive behavior, which is a unique interpretation of observing.

Rate dependency may provide a description of effects of $d$-amp on observing, but it does not entail or exclude a behavioral or biological mechanism (Branch, 1984; Raiff \& Dallery, 2008). Rate dependency is a correlation between the proportional effects of a drug on observing rates relative to saline observing rates (i.e., a relation between two dependent variables). Effects of $d$-amp on observing rates may be constrained by baseline observing rates, but not caused or determined by them (McKearney, 1981). Rate dependency is a description of an empirical 
relation, but does not preclude increases in observing within the terminal link to be related to enhancement of conditioned reinforcer efficacy of the terminal-link stimulus.

\section{Morphine and Observing}

Drugs outside the stimulant drug class typically have not been found to increase responding for a conditioned reinforcer (Beninger \& Ranaldi, 1994; Sutton \& Beninger, 1999). Within the opioid drug class, Robbins, Watson, Gaskin, and Ennis (1983) found decreases in responding for a food-paired stimulus during a food-extinction condition after morphine administration in rats. Kelly and Thompson (1985) found methadone administration decreased responding for a brief food-paired stimulus under a second-order schedule of reinforcement in pigeons. In the present experiment, morphine was administered as a potential negative control based on past research. Effects of morphine on observing in the present study were generally consistent with effects of $d$-amp on observing. Observing rates tended to decrease in a dosedependent manner within the initial and middle links and increase at 3.0 or $5.6 \mathrm{mg} / \mathrm{kg}$ morphine for three of four subjects within the terminal link. Thus, a general rate-dependent effect was also observed with morphine, which has been reported previously (e.g., Knealing \& Schaal, 2002). The congruent results from morphine and $d$-amp tests coupled with the rate-dependency analysis are not supportive of a conditioned reinforcement enhancement effect.

\section{Conclusion}

Overall, the similar results found between effects of morphine and $d$-amp on observing may be best described as rate dependent. The nature of the baseline schedule, and the pattern of behavior engendered by it, may have limited the potential to observe a conditioned reinforcement effect. Predictions based upon the delay-reduction hypothesis would hold that only the terminallink stimulus should function as conditioned reinforcer despite the suggestion that all stimuli 
within a chain schedule may have conditioned-reinforcing value (Hendry \& Dillow, 1966).

Thus, the potential to observe enhancement of conditioned reinforcement effects may have been limited to one link. There was no consistent finding of increased observing across subjects and drugs within the initial and middle links. For two subjects within the terminal link there were increases in observing rates at $1.0 \mathrm{mg} / \mathrm{kg} d$-amp, but those findings also fit within the framework of rate dependency. The pattern of behavior within the terminal link (i.e., superstitious behavior) and the disruption of it may have contributed to the consistent results found between $d$-amp and morphine. Future research to address this general issue may include an increase in the number of link stimuli (e.g., six links instead of three) while keeping the reinforcement rate constant. Under this arrangement, more stimuli would be predicted to function as conditioned reinforcers based upon the principle of delay reduction, but may not be contaminated by competition with superstitious behavior.

It is assumed that enhancement of the effectiveness of a conditioned reinforcer is modulated by the administration of a drug from the stimulant drug class. In the present study, increases in observing were not selective for a particular drug class (see also Branch, 1975). In addition, both Kelleher, Riddle and Cook (1962) and Dearing and Branch (1981) found that chlorpromazine generally decreased responding maintained by food, but increased observing of stimuli correlated with alternating components of food and extinction in pigeons. In fact, Thomas (1966) also found increased responding maintained by a conditioned reinforcer after administration of chloropromazine when comparing performance under chain versus tandem schedules (see also Marr, 1970). Chloropromazine is a dopamine antagonist, whereas the majority of stimulant drugs are some form of dopamine agonists. The research concerning chlorpromazine has not been included with recent reviews of conditioned reinforcement (see 
Beninger \& Ranaldi, 1994; Sutton \& Beninger, 1999), and it is unclear how the findings would be reconciled. The majority of experimental evidence, however, points towards a stimulant hypothesis (mainly through D1-receptor mediation, see Sutton \& Beninger, 1999). The congruent results between $d$-amp and morphine are largely inconsistent with past research on conditioned reinforcement, but fit well within the framework of rate dependence.

\section{General Discussion}

Responding in early links of a chain may be maintained by the conditioned-reinforcing value of stimulus onset accompanied by subsequent links (Kelleher \& Gollub, 1962) or responding within each link of a chain may be controlled exclusively by the discriminative value of the link stimuli signaling the delay to primary reinforcement (Staddon \& Cerutti, 2003). In the present set of experiments, observing was maintained by the production of stimuli correlated with links of a chain VT schedule, indicating conditioned-reinforcing properties of all or some of chain stimuli (see also Hendry \& Dillow, 1966; Kendall, 1972; Auge, 1977). To test if performance under chain schedules was maintained by a backward transmission of reinforcer value (i.e., a classical-conditioning interpretation of chain performance), extinction and prefeeding conditions were implemented. No evidence of a backward transmission of reinforcer value was found when examining either the entire chain or just the first two links. Observing decreased the least within the terminal link and the rate of decrease within the initial and middle links was approximately the same. The results from extinction and prefeeding conditions, however, were generally consistent with predictions based on the delay-reduction hypothesis of conditioned reinforcement. In Experiment 2, effects of $d$-amp and morphine were tested to determine if the conditioned reinforcer efficacy of chain stimuli would be enhanced selectively by administration of a stimulant drug. Results did not support prior literature (Beninger \& 
Ranaldi, 1994; Sutton \& Beninger, 1999) suggesting that only stimulant drugs enhance the efficacy of conditioned reinforcers, but were supportive of a rate-dependency interpretation.

A common link between both experiments is the qualitative similarity in effects of extinction, prefeeding, and $d$-amp and morphine administration on observing. For each type of disruptor, it was the general case across subjects that observing rates decreased within the initial and middle links and increased at some point within the terminal link (subject C4 was an exception during the prefeeding condition and subject D4 during morphine tests). Results from both Experiments 1 and 2 appear to be consistent with a general disruption of the ongoing behavioral sequence no matter the type of disruptor (see Schaal, Miller, \& Odum, 1995; Odum \& Schaal, 2000 for a discussion of the generality of effects between drug and nondrug disruptors). Effects of disruptors on behavior have generally fit within the framework of behavioral momentum and resistance-to-change. Behavioral momentum theory (Nevin, 1992) suggests resistance-to-change is a function of the reinforcement rate within a particular context (i.e., the Pavlovian stimulus-reinforcer relation is critical). A behavioral momentum analysis related to the rate of primary or conditioned reinforcement (see Shahan \& Podlesnik, 2008) in the present studies, however, would be premature. For the latter case, observing was maintained by the production of stimuli correlated with links of a chain, but it does not follow that each link stimulus served as a conditioned reinforcer (as an example see Dinsmoor, 1983 and Escobar \& Bruner, 2009 for a discussion of the conditioned-reinforcing value of stimuli correlated with food vs. extinction components of a multiple schedule). In addition, the nature of the terminal-link sequence of behavior is not clear. 


\section{Terminal-link Behavior}

In the present set of experiments, food was delivered on a response-independent basis partly to lessen competition between two operative responses and provide a more clear assessment of conditioned reinforcement effects. Observing of chain/serial stimuli tends to decrease during the last link prior to food delivery with response-dependent food schedules (Hendry \& Dillow, 1966; Kendall, 1972; Branch 1975). There is evidence that this decline is not exclusive under response-dependent food conditions. Dinsmoor, Dougan, Pfister, and Thiels (1992) in Experiment 3 examined autoshaped pecking in which four colors were consistently presented prior to food delivery in a chain sequence. Each sequence consisted of seven components and each component averaged $30 \mathrm{~s}$. The first color was present during the first four components followed by the remaining three colors within the next three components until food was delivered independent of behavior. For the majority of subjects, pecking peaked during the $6^{\text {th }}$ component. When only two stimuli were used (e.g., white during first four components, red during last three components), pecking peaked during the $5^{\text {th }}$ component. A critical finding was that pecking decreased on average $60 \mathrm{~s}$ prior to food (and in the present experiments, observing stopped around an average of $55 \mathrm{~s}$ or $32.5 \mathrm{~s}$ prior to food depending upon average link duration). It was concluded that the early peak in pecking relative to food delivery "may represent a pervasive phenomenon but one that does not seem predictable from existing theoretical accounts" (Dinsmoor et al., 1992, p.275).

Palya (1993) has a developed a model that potentially fits the pattern of baseline observing found in the current experiments. Similar to the work of Dinsmoor, Lee and Brown (1986), Palya demonstrated that stimuli correlated with early portions of a fixed-clocked, interfood interval (60 s in duration composed of 10 serial stimuli) maintained escape via a 
negative observing response (i.e., a peck turned off the key light) and stimuli closer to food were produced by an observing response. He also found for four out of five subjects that observing decreased for the production of the last serial stimulus, while elicited pecking of the terminal stimulus persisted. Although the procedure was complex and certain difficulties were involved with establishing observing that are beyond the present discussion, the results were interpretable with a bipolar model of behavior within clocked interfood intervals.

Performance under baseline conditions in the present study (low observing rates in the terminal link relative to the initial and middle links) may be compatible with a bipolar model of behavior within a clocked interfood interval (Palya \& Bowers, 2003). In the typical clocked interfood interval arrangement, serial stimuli are presented within a specific period of time until food is delivered independent of a required response (similar to Dinsmoor et al., 1992). The bipolar model would hold that "stimuli correlated with the maximum likelihood of the reinforcer would control terminal behavior, whereas stimuli correlated with the minimum likelihood of the reinforcer would control some other behavior, such as escape, inhibition, or an element from a different behavior system" (Palya \& Bowers, 2003, p.33).

In the present studies, terminal behavior mainly consisted of pacing along the front panel or pecking at a corner of the front panel after observing the terminal-link stimulus once or twice. This overall pattern of terminal behavior has been commonly observed in studies pertaining to the analysis of superstitious behavior (e.g., Staddon \& Simmelhag, 1971; Timberlake \& Lucas, 1985). Thus, the terminal-link stimulus, which was more predictive of food than any other exteroceptive stimulus, may have controlled a specific pattern of behavior that was engendered by a response-independent VT chain schedule. Stimuli correlated with a lower probability of food (initial- and middle-link stimuli) controlled another pattern of behavior (observing). 
Observing of early link stimuli is not compatible with behavior such as escape or avoidance, but appears not to be excluded within the bipolar model. The present set of experiments were not designed to investigate a bipolar model of behavior within an interfood clock, therefore this conclusion is tentative at best.

The functional nature of the terminal behavior (i.e., superstitious behavior) is not clearly addressed by present or past research, although it has been assumed to be adventitiously maintained. Skinner's (1948) original conception was that behavior under response-independent food conditions may become adventitiously reinforced, but Timberlake and Lucas (1985) have argued that terminal behavior is species-typical behavior (related to obtaining food) that is elicited by environmental cues. The present experiments were also not designed to assess the importance of operant vs. Pavlovian processes in maintaining superstitious behavior. The orderly effects of each disruptor, however, suggest that each manipulation was altering a common behavioral mechanism. The factors responsible for this orderliness warrant further investigation. 


\section{References}

Auge, R. J. (1977). Stimulus functions within a fixed-interval clock schedule: Reinforcement, punishment, and discriminative stimulus control. Animal Learning \& Behavior, 5, 117 123.

Bell, M. C., Goldenberg, M., \& McDevitt, M. A. (2007). The influence of intertrial interval food on extinction and devaluation in chain schedules. The Journal of General Psychology, 134, 133-151.

Bell, M. C., \& Gomez, B. E. (2008). Effect of unsignaled delays between stimuli in a chain schedule on responding and resistance to change. Behavioural Processes, 77, 343-350.

Beninger, R. J., \& Ranaldi, R. (1994). Dopaminergic agents with different mechanisms of action differentially affect responding for conditioned reward. In T. Palomo \& A. Trevor (Eds), Strategies for studying brain disorders: Depressive, anxiety and drug abuse disorders p.411-428). Madrid: Editiorial Complutense \& London: Farrand Press.

Bond, N. W., Sanger, D. J., \& Blackman, D. E. (1975). Effects of $d$-amphetamine on the behavior of pigeons maintained by a second-order schedule of reinforcement. The Journal of Pharmacology and Experimental Therapeutics, 194, 327-331.

Branch, M. B. (1975). Effects of chlorpromazine and d-amphetamine on observing response during a fixed-interval schedule. Psychopharmacologia, 42, 87-93.

Branch, M. B. (1984). Rate dependency, behavioral mechanisms, and behavioral pharmacology. Journal of the Experimental Analysis of Behavior, 42, 511-522.

Case, D. A., \& Fantino, E. (1981). The delay-reduction hypothesis of conditioned reinforcement and punishment: Observing behavior. Journal of the Experimental Analysis of Behavior, 35, 93-108. 
Catania, C. A., Yohalem, R., \& Silverman, P. J. (1980). Contingency and stimulus change in chained schedules of reinforcement. Journal of the Experimental Analysis of Behavior, $33,213-219$.

Clark, F. C. (1969). Effects of $d$-amphetamine on observing behavior in the squirrel monkey. Journal of the Experimental Analysis of Behavior, 12, 977-987.

Cohen, S. L., \& Branch, M. N. (1991). Food-paired stimuli as conditioned reinforcers: Effects of d-amphetamine. Journal of the Experimental Analysis of Behavior, 56, 277-288.

Dearing, M. E., \& Branch, M. N. (1981). Effects of chlorpromazine on food-maintained and observing behavior. Psychopharmacology, 73, 281-285.

DeFulio, A., \& Hackenberg, T. D. (2008). Combinations of response-dependent and responseindependent schedule-correlated stimulus presentations in an observing procedure. Journal of the Experimental Analysis of Behavior, 89, 299-309.

Dinsmoor, J. A. (1983). Observing and conditioned reinforcement. Behavioral and Brain Sciences, 6, 693-728.

Dinsmoor, J. A., Bowe, C. A., Green, L., \& Hanson, J. (1988). Information on response requirements compared with information on food density as a reinforcer of observing in pigeons. Journal of the Experimental Analysis of Behavior, 49, 229-237.

Dinsmoor, J. A., Lee, D. M., \& Brown, M. M. (1986). Escape from serial stimuli leading to food. Journal of the Experimental Analysis of Behavior, 46, 259-279.

Disnmoor, J. A., Dougan, J. D., Pfister, J., \& Thiels, E. (1992). The autoshaping procedure as a residual block clock. Journal of the Experimental Analysis of Behavior, 58, 265-276. 
Escobar, R., \& Bruner, C. (2009). Observing responses and serial stimuli: Searching for the reinforcing properties of the S-. Journal of the Experimental Analysis of Behavior, 92, 215-231.

Fantino, E. (1977). Conditioned reinforcement: Choice and information. In W.K. Honig \& J.E.R. Staddon (Eds.), Handbook of operant behavior (p. 313-339). Englewood Cliffs, NJ: Prentice-Hall.

Fantino, E., \& Case, D. A. (1983). Human observing: Maintained by correlated stimuli with reinforcement but not extinction. Journal of the Experimental Analysis of Behavior, 40, 193-210.

Files, F. J., Branch, M. N., \& Clody, D. (1989). Effects of methylphenidate on responding under extinction in the presence and absence of conditioned reinforcement. Behavioural Pharmacology, 1, 113-121.

Hendry, D. P., \& Dillow, P. V. (1966). Observing behavior during interval schedules. Journal of the Experimental Analysis of Behavior, 9, 337-349.

Kelleher, R. T., \& Fry, W. T. (1962). Stimulus functions in chained fixed-interval schedules. Journal of the Experimental Analysis of Behavior, 5, 169-173.

Kelleher, R. T., Riddle, W. C., \& Cook, L. (1962). Observing responses in pigeons. Journal of the Experimental Analysis of Behavior, 5, 3-13.

Kelleher, R. T., \& Gollub, L. R. (1962). A review of positive conditioned reinforcement. Journal of the Experimental Analysis of Behavior, 5, 543-597.

Kelly, T. H., \& Thompson, T. (1985). The effects of methadone on operant behavior maintained with and without conditioned reinforcement in the pigeon. Psychopharmacology, 86, 212-216. 
Kendall, S. B., (1965). The distribution of observing responses in a mixed FI-FR schedule. Journal of the Experimental Analysis of Behavior, 8, 305-312.

Kendall, S. B. (1972). Some effects of response-dependent clock stimuli in a fixed-interval schedule. Journal of the Experimental Analysis of Behavior, 17, 161-168.

Knealing, T. W., \& Schaal, D. W. (2002). Disruption of temporally organized behavior by morphine. Journal of the Experimental Analysis of Behavior, 77, 157-169.

Lieving, G. A., Reilly, M. P., \& Lattal, K. A. (2006). Disruption of responding maintained by conditioned reinforcement: Alterations in response-conditioned-reinforcer relations. Journal of the Experimental Analysis of Behavior, 86, 197-209.

Marr, M. J. (1970). Effects of chlorpromazine in the pigeon under a second-order schedule of food presentation. Journal of the Experimental Analysis of Behavior, 13, 291-299.

Mazurski, E. J., \& Beninger, R. J. (1986). The effects of (+)-amphetamine and apomorphine on responding for a conditioned reinforcer. Psychopharmacology, 90, 239-243.

McKearney, J. W. (1981). Rate dependency: Scope and limitations in the explanation and analysis of the behavioral effects of drugs. In T. Thompson, PB Dews, and WA McKim (Eds), Advances in Behavioral Pharmacology (vol. 3) (p.91-109). New York: Academic Press.

Neuringer, A. J. (1970). Superstitious key pecking after three peck-produced reinforcements. Journal of the Experimental Analysis of Behavior, 13, 127-134.

Nevin, J. A. (1992). An integrative model for the study of behavioral momentum. Journal of the Experimental Analysis of Behavior, 57, 301-316. 
Nevin, J. A., Mandell, C., \& Yarensky, P. (1981). Response rate and resistance to change in chained schedules. Journal of Experimental Psychology: Animal Behavior Processes, 7, 278-294.

Northup, J., Fusilier, I., Swanson, V., Roane, H., \& Borrero, J. (1997). An evaluation of methylphenidate as a potential establishing operation for some common classroom reinforcers. Journal of Applied Behavior Analysis, 30, 615-625.

Odum, A. L., \& Schaal, D. W. (2000). The effects of morphine on fixed-interval patterning and temporal discrimination. Journal of the Experimental Analysis of Behavior, 74, 229-243.

Palya, W. L. (1993). Bipolar control in fixed interfood intervals. Journal of the Experimental Analysis of Behavior, 60, 345-359.

Palya, W. L., \& Bowes, M. T. (2003). Stimulus control in fixed interfood intervals. Learning \& Behavior, 31, 22-34.

Raiff, B. R., \& Dallery, J. (2006). Effects of acute and chronic nicotine on responses maintained by primary and conditioned reinforcers in rats. Experimental and Clinical Psychopharmacology, 14, 296-305.

Raiff, B. R., \& Dallery, J. (2008). The generality of nicotine as a reinforce enhancer in rats: Effects on responding maintained by primary and conditioned reinforcers and resistance to extinction. Psychopharmacology, 201, 305-314.

Ranaldi, R., \& Beninger, R. J. (1993). Dopamine D1 and D2 antagonists attenuate amphetamineproduced enhancement of responding for conditioned reward in rats. Psychopharmacology, 113, 110-118. 
Robbins, T. W., Watson, B. A., Gaskin, M., \& Ennis, C. (1983). Contrasting interactions of pipradol, $d$-amphetamine, cocaine, cocaine analogues, apomorphine and other drugs with conditioned reinforcement. Psychopharmacology, 80, 113-119.

Royalty, P., Williams, B. A., \& Fantino, E. (1987). Effects of delayed conditioned reinforcement in chained schedules. Journal of the Experimental Analysis of Behavior, 47, 41-56.

Sanger, D. J., \& Blackman, D. E. (1976). Rate-dependent effects of drugs: A review of the literature. Pharmacology, Biochemistry, \& Behavior, 4, 73-83.

Schaal. D. W., Miller, M. A., \& Odum, A. L. (1995). Cocaine's effects on food-reinforced pecking in pigeons depend on food deprivation level. Journal of the Experimental Analysis of Behavior, 64, 61-73.

Sizemore, O. J., \& Lattal, K. A. (1978). Unsignalled delay of reinforcement in variable-interval schedules. Journal of the Experimental Analysis of Behavior, 30, 169-175.

Shahan, T. A. (2002). Observing behavior: Effects of rate and magnitude of primary reinforcement. Journal of the Experimental Analysis of Behavior, 78, 161-178.

Shahan, T. A., \& Podlesnik, C. A. (2008). Conditioned reinforcement value and resistance to change. Journal of the Experimental Analysis of Behavior, 89, 263-298.

Skinner, B. F. (1948). Superstition in the pigeon. Journal of Experimental Psychology, 38, 168172.

Staddon, J. E. R. (1992). The superstition experiment: A reversible figure. Journal of Experimental Psychology: General, 121, 270-272.

Staddon, J. E. R., \& Simmelhag, V. L. (1971). The superstition experiment: A reexamination of its implications for the principles of adaptive behavior. Psychological Review, 78, 3-43. 
Staddon, J. E. R., \& Cerutti, D. T. (2003). Operant conditioning. Annual Review of Psychology, 54, 115-144.

Sutton, M. A., \& Beninger, R. J. (1999). Psychopharmacology of conditioned reward: Evidence for a rewarding signal at d1-link dopamine receptors. Psychopharmacology, 144, 95110.

Thomas, J. R. (1966). Differential effects of two phenothiazines on chain and tandem schedule performance. Journal of Pharmacology and Experimental Therapeutics, 152, 354-361.

Timberlake, W., \& Lucas, G. A. (1985). The basis of superstitious behavior: Chance contingency, stimulus substitution, or appetitive behavior? Journal of the Experimental Analysis of Behavior, 44, 279-299.

Tomanari, G. Y., Machado, L. M., \& Dube, W. V. (1998). Pigeons’ observing behavior and response-independent food presentations. Learning and Motivation, 29, 249-260.

Williams, B. A. (1994). Conditioned reinforcement: Experimental and theoretical issues. The Behavior Analyst, 17, 261-285.

Williams, B. A., Ploog, B. O., \& Bell, M. C. (1995). Stimulus devaluation and extinction of chain schedule performance. Animal Learning \& Behavior, 23, 104-114.

Williams, B. A. (1997). Conditioned reinforcement dynamics in three-link chained schedules. Journal of the Experimental Analysis of Behavior, 67, 145-159.

Williams, B. A. (1999). Value transmission in discrimination learning involving stimulus chains. Journal of the Experimental Analysis of Behavior, 72, 177-185.

Williams, D. R., \& Williams, H. (1969). Auto-maintenance in the pigeon: Sustained pecking despite contingent non-reinforcement. Journal of the Experimental Analysis of Behavior, $12,511-520$. 
Wyckoff, L. B., Jr. (1952). The role of observing responses in discrimination learning: Part I. Psychological Review, 59, 431-442.

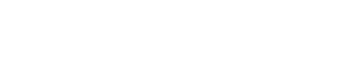
Hagen 